Atmos. Chem. Phys., 17, 12725-12742, 2017

https://doi.org/10.5194/acp-17-12725-2017

(C) Author(s) 2017. This work is distributed under

the Creative Commons Attribution 3.0 License.

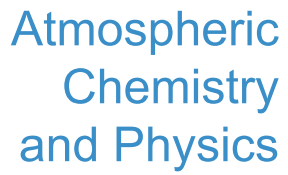

(c) (i)

\title{
Impacts of solar-absorbing aerosol layers on the transition of stratocumulus to trade cumulus clouds
}

\author{
Xiaoli Zhou ${ }^{1}$, Andrew S. Ackerman ${ }^{2}$, Ann M. Fridlind ${ }^{2}$, Robert Wood ${ }^{3}$, and Pavlos Kollias ${ }^{4,5}$ \\ ${ }^{1}$ Department of Atmospheric and Oceanic Sciences, McGill University, Montreal, Quebec, Canada \\ ${ }^{2}$ NASA Goddard Institute for Space Studies, New York, New York, USA \\ ${ }^{3}$ Department of Atmospheric Sciences, University of Washington, Seattle, Washington, USA \\ ${ }^{4}$ School of Marine and Atmospheric Sciences, Stony Brook University, Stony Brook, New York, USA \\ ${ }^{5}$ Department of Environmental and Climate Sciences, Brookhaven National Laboratory, Upton, New York, USA
}

Correspondence: Xiaoli Zhou (xiaoli.zhou@mail.mcgill.ca)

Received: 19 March 2017 - Discussion started: 3 May 2017

Revised: 17 August 2017 - Accepted: 30 August 2017 - Published: 26 October 2017

\begin{abstract}
The effects of an initially overlying layer of solarabsorbing aerosol on the transition of stratocumulus to trade cumulus clouds are examined using large-eddy simulations. For lightly drizzling cloud the transition is generally hastened, resulting mainly from increased cloud droplet number concentration $\left(N_{\mathrm{c}}\right)$ induced by entrained aerosol. The increased $N_{\mathrm{c}}$ slows sedimentation of cloud droplets and shortens their relaxation time for diffusional growth, both of which accelerate entrainment of overlying air and thereby stratocumulus breakup. However, the decrease in albedo from cloud breakup is more than offset by redistributing cloud water over a greater number of droplets, such that the diurnal-average shortwave forcing at the top of the atmosphere is negative. The negative radiative forcing is enhanced by sizable longwave contributions, which result from the greater cloud breakup and a reduced boundary layer height associated with aerosol heating. A perturbation of moisture instead of aerosol aloft leads to a greater liquid water path and a more gradual transition. Adding absorbing aerosol to that atmosphere results in substantial reductions in liquid water path (LWP) and cloud cover that lead to positive shortwave and negative longwave forcings on average canceling each other. Only for heavily drizzling clouds is the breakup delayed, as inhibition of precipitation overcomes cloud water loss from enhanced entrainment. Considering these simulations as an imperfect proxy for biomass burning plumes influencing Namibian stratocumulus, we expect regional indirect plus semi-direct forcings to be substantially negative to negligible at the top of the atmosphere, with its magnitude sensitive to background and perturbation properties.
\end{abstract}

\section{Introduction}

Aerosols affect the earth's radiation budget in at least three ways. First, they directly absorb and scatter solar radiation. Second, they affect radiative fluxes indirectly through their role as cloud condensation nuclei, influencing cloud microphysics and thereby affecting cloud albedo and cloud cover. Third, solar-absorbing aerosols can alter atmospheric heating rates and stability, leading to rapid adjustments in cloud properties; the resulting impact on radiative fluxes is referred to as the semi-direct effect (Hansen et al., 1997).

Aerosols have been identified as contributing the greatest uncertainty to anthropogenic climate forcing (Forster et al., 2007). For instance, the observational study of the Indian Ocean Experiment (INDOEX) (Jayaraman et al., 1998; Satheesh and Ramanathan, 2000) and some general circulation model (GCM) studies (e.g., Hansen et al., 1997; Lohmann and Feichter, 2001; Jacobson, 2002; Cook and Highwood, 2004) have found a net decrease in low-level cloud cover when solar-absorbing aerosols are present, which corresponds to a positive radiative forcing at the top of the atmosphere (TOA) that tends to warm the climate system, while other observational studies (e.g., Loeb and Schuster, 2008; Wilcox, 2010; Adebiyi et al., 2015, hereafter A15) have found the opposite, in which the cloud cover increases. Some GCM studies (e.g., Menon et al., 2002; Penner et al., 2003; Sakaeda et al., 2011) have found that the radiative forcing depends crucially on the height of the absorbing aerosol. To better constrain radiative forcing in climate models, a comprehensive understanding of regional cloud- 
aerosol interactions and the corresponding radiative forcings is of value.

Here we focus on warm (liquid-phase) clouds in the planetary boundary layer (PBL). Higher-level clouds are not considered. Process-level understanding of the physical mechanisms underlying indirect and semi-direct aerosol radiative forcings has been largely advanced through studies with large-eddy simulation (LES) models and in situ observations. Regarding aerosol indirect forcing, with all else equal (particularly cloud cover and liquid water path), increased cloud droplet number concentration $\left(N_{\mathrm{c}}\right)$ resulting from increased aerosol concentration $\left(N_{\mathrm{a}}\right)$ increases cloud optical thickness and thus albedo, thereby exerting a negative radiative forcing at TOA (Twomey, 1974, 1991). For precipitating clouds, increasing $N_{\mathrm{c}}$ can reduce precipitation and thereby enhance liquid water path (LWP) and cloud cover (e.g., Albrecht, 1989; Ackerman et al., 1993; Pincus and Baker, 1994; Hindman et al., 1994). However, for clouds with little precipitation, modeling studies indicate that increased $N_{\mathrm{c}}$ tends to reduce LWP and cloud cover by increasing PBL entrainment (Ackerman et al., 2004, 2009; Wood, 2007), which can dry the PBL and reduce LWP when the overlying air is sufficiently dry (Randall et al., 1984). Such a tendency is consistent with satellite observations of LWP reduction in ship tracks, on average (Coakley Jr. and Walsh, 2002). At least three microphysical mechanisms have been found to play a role in the entrainment increase. First, in what we shall refer to as the "sedimentation effect", increased $N_{\mathrm{c}}$ leads to smaller droplets that fall more slowly, which increases the amount of cloud water available for evaporative cooling during entrainment events, thereby strengthening entrainment (Bretherton et al., 2007). Second, in what we shall refer to as the "evaporation effect", smaller droplets increase the total surface area of cloud droplets, accelerating evaporation and driving stronger entrainment (Xue et al., 2008). Third, increased $N_{\mathrm{c}}$ also suppresses drizzle, enhancing convective intensity and entrainment (e.g., Stevens et al., 1998; Wood, 2007). Under dry overlying air, all three effects tend to reduce cloud cover and LWP, leading to a positive radiative forcing. However, if the entrained air is sufficiently moist, entrainment can be expected to increase LWP (Randall et al., 1984).

Aerosol semi-direct effects have been studied by Ackerman et al. (2000) in the context of trade cumulus under a sharp inversion, in which absorbing aerosol within the boundary layer increases solar heating in a manner that stabilizes the PBL, reducing the moisture supply from the surface and the amount of cloudiness, leading to a positive radiative forcing at TOA. More directly in such a scenario the relative humidity of the PBL is reduced by enhanced solar heating, reducing cloudiness as originally found in global model simulations by Hansen et al. (1997). In contrast, Johnson et al. (2004) conducted large-eddy simulations of marine stratocumulus and found that an absorbing aerosol immediately above the PBL (and not entrained) strengthens the in- version, reducing entrainment and thereby increasing cloud cover, leading to a negative radiative forcing, while they found the opposite (positive radiative forcing) for aerosol heating within the PBL. That study was motivated at least in part by measurements of absorbing aerosol from biomass burning advected from Africa over Namibian stratocumulus, where biomass burning aerosol plumes may also be well separated from the PBL (Keil and Haywood, 2003; J. M. Haywood et al., 2003), a factor that has been found to be critical to absorbing aerosol effects on cloud fraction (Feingold et al., 2005).

Further complexity arises when considering the possibility that absorbing aerosol can act as cloud condensation nuclei $(\mathrm{CCN})$ and thereby increase $N_{\mathrm{c}}$, which was neglected in the early studies of Johnson et al. (2004) and Feingold et al. (2005) and only represented quite crudely by Ackerman et al. (2000), who simply imposed a sequence of uniform $N_{\mathrm{c}}$ values in their simulations. Here we will consider both roles of absorbing aerosol.

By considering two trade cumulus regimes, one transitional case with a sharp inversion (ATEX) and a more downstream case with greatly reduced cloud cover (BOMEX), Johnson (2005) found the semi-direct aerosol forcing to depend strongly on the cloud regime, with the magnitude of the forcing increasing with (unperturbed) cloud cover. This regime dependence is relevant to the stratocumulusto-cumulus transition (SCT), a climatological feature downstream of subtropical marine stratocumulus (Klein and Hartmann, 1993; Sandu et al., 2010; Zhou et al., 2015). The SCT has been found in modeling studies to be driven by easterly, equatorward advection over increasing sea surface temperatures (SSTs), which increases surface latent heat fluxes, enhancing buoyancy fluxes in the cloud layer and hence entrainment. The PBL deepening from progressive entrainment inhibits the ability of circulations forced at cloud top to maintain a well-mixed boundary layer, reducing the surface moisture supply and eventually drying out the stratocumulus clouds (Bretherton and Wyant, 1997; Wyant et al., 1997). A recent observational study has found that the timescale of the SCT over the eastern Pacific can depart considerably from that in an idealized model framework driven only by increasing SST (Zhou et al., 2015), suggesting that other factors, such as meteorological variability, might play important roles in the timescale of the SCT. Yamaguchi et al. (2015) (hereafter Y15) investigated the impact of overlying absorbing aerosol and associated enhanced moisture on the SCT and found that entrained absorbing aerosol in general delays the SCT, with a net negative change in TOA shortwave (SW) cloud radiative forcing (CRF).

It has been documented in recent observational studies near northern Namibia and remote St. Helena in the South Atlantic that the sampled absorbing aerosol is often accompanied by enhanced humidity, with an average moisture perturbation of $\sim 1 \mathrm{~g} \mathrm{~kg}^{-1}$ relative to the underlying air (J. M. Haywood et al., 2003; A15). This humidity is asso- 
ciated with the outflow from the deep, continental boundary layer, and accompanies the absorbing aerosol that results from biomass burning. The enhanced humidity induces additional radiative heating, which can regulate cloud processes by reducing cloud-top longwave (LW) cooling (A15) and by simply reducing the dryness of air entrained into the PBL. Y15 located a stationary moist layer above the PBL and found that the additional moisture itself enhances cloud breakup during the SCT, although they acknowledge that their perturbation of $\sim 3 \mathrm{~g} \mathrm{~kg}^{-1}$ likely represents an upper limit compared with A15. We note that in our modeling framework it is simply assumed that the model domain is advected equatorward by the trade winds, thus implicitly treating the flow aloft as being easterly, despite observations that indicate the circulation over the South Atlantic to be far more complex (e.g., Adebiyi and Zuidema, 2016).

Here we perform an expanded investigation of the impact of absorbing aerosol and moisture on the SCT. Because Y15 was published during the course of this work, our simulation setups are similar but not identical, and we highlight similarities and differences below. Like Y15, we adopt the Sandu and Stevens (2011) SCT case study, with some modifications. Here we separate the responses to aerosol heating above and within the PBL and on microphysical processes. We consider the impacts on lightly and heavily drizzling stratocumulus decks. We also assess the impacts of additional overlying moisture on the SCT and how it influences the effects of absorbing aerosol. The radiative forcings in our study consider changes in not only SW but also LW fluxes. Our results differ from Y15 in that initially overlying plumes of absorbing aerosol lead to positive changes in SW CRF at TOA, and the aerosol and moisture perturbations never delay the SCT in our simulations (unless we omit well-established physical processes).

The remainder of this paper is organized as follows. Section 2 documents the model setup and case description. Section 3 presents analysis of the microphysical and heating effects of absorbing aerosol during the transition of lightly drizzling stratocumulus. In Sect. 4, we investigate the impact of additional moisture in the aerosol layer, and the influence of the initial altitude of the moist aerosol layer. The impacts of an absorbing aerosol on the SCT of heavily drizzling stratocumulus are discussed in Sect. 5. In Sect. 6 we discuss and summarize our findings.

\section{Model setup and simulated cases}

The Distributed Hydrodynamic Aerosol and Radiative Modeling Application (DHARMA) (Ackerman et al., 2004, and references therein) simulations here are based on the "reference case" 3-day Lagrangian SCT setup of Sandu and Stevens (2011). The basis for the case is a composite of the large-scale conditions encountered along trajectories over the northeastern Pacific from June to August of 2006 and
2007. Following Sandu and Stevens (2011) and de Roode et al. (2016), SST increases steadily from $293.75 \mathrm{~K}$ at $0 \mathrm{~h}$ to $299.17 \mathrm{~K}$ at $72 \mathrm{~h}$, and a uniform divergence of large-scale horizontal winds of $1.86 \times 10^{-6} \mathrm{~s}^{-1}$ is imposed up to an altitude of $2000 \mathrm{~m}$, above which the large-scale subsidence is constant. Because the large-scale subsidence is imposed rather than interactive, we omit any possible decrease in subsidence associated with solar heating by absorbing aerosol (cf. Sakaeda et al., 2011). An intercomparison of six different LES models shows that DHARMA results are consistent with others in representing the SCT (de Roode et al., 2016), although differences between models do exist, as discussed further below. Unlike Sandu and Stevens (2011) and Y15, here we begin simulations at midnight local time (when turbulent mixing is vigorous, to accelerate spin-up) rather than 10:00 local time. Surface fluxes are computed following similarity theory as in Ackerman et al. (1995). Note that because sea surface temperature is prescribed, it is not impacted by changes in the overlying atmosphere.

The DHARMA domain size is $10.8 \mathrm{~km} \times 10.8 \mathrm{~km} \times 3.2 \mathrm{~km}$ and horizontal resolution is set to $\Delta x=\Delta y=75 \mathrm{~m}$. Vertically 240 levels are distributed between 0 and $3200 \mathrm{~m}$, with variable vertical resolution ranging from $30 \mathrm{~m}$ near the surface to $10 \mathrm{~m}$ near the inversion and up to $60 \mathrm{~m}$ near the model top; before using this grid with twice as coarse of a grid as in de Roode et al. (2016), we confirmed that the DHARMA results were not sensitive to the difference. The microphysics scheme is an adaptation of the two-moment scheme of Morrison et al. (2005) with prognostic saturation excess following Morrison and Grabowski (2008) and assuming the shape factor of the cloud droplet size distribution to be 10.3 (equivalent to relative dispersion of 0.3 ) following Geoffroy et al. (2010). Radiative transfer is calculated for each column every minute using a two-stream model (Toon et al., 1989). An isothermal layer for the radiative transfer calculations overlies the LES grid, with an ozone column following the specifications of de Roode et al. (2016) and with temperature $(180 \mathrm{~K})$ and water vapor column $\left(0.5 \mathrm{~g} \mathrm{~cm}^{-2}\right)$ chosen to match the profile of downwelling LW flux of the other models in the intercomparison. The ocean surface albedo is spectrally uniform at $7 \%$. Activation of aerosol follows AbdulRazzak and Ghan (2000) using supersaturation computed after the condensational adjustment of Eq. (A10) in Morrison and Grabowski (2008). The number and mass concentrations of cloud droplet and raindrops are prognostic in the twomoment cloud microphysics scheme, but for aerosol it is only the number concentration of unactivated plus activated particles for each aerosol species that is prognostic; there is no evolution of the size and breadth of the underlying aerosol size distribution for each species, nor are there sources or sinks of aerosol number.

Two species of aerosol are prescribed: ammonium sulfate and a solar-absorbing aerosol; both aerosol types act as CCN and interact with the radiation before and after activation. The optical properties for aerosol particles and hydromete- 
ors are computed following Ackerman et al. (1995) using Mie calculations on a 25-bin grid with geometric spacing, in which we average over six sub-intervals within each bin to smooth any Mie resonances. Soot cores with a fixed size are included in the Mie calculations for solar-absorbing aerosol (following Ackerman et al., 2000) as well as for the fraction of cloud droplets in each grid cell that activated on solarabsorbing CCN. The baseline case is an ensemble of three simulations with different pseudo-random seeds for the initial temperature perturbation field in the PBL, and includes only ammonium sulfate aerosol, which is uniformly distributed in the vertical with $N_{\mathrm{a}}$, sulfate $=150 \mathrm{mg}^{-1}$ (without a vertical gradient, the aerosol scheme is completely diagnostic). Further simulations are conducted that incorporate an absorbing aerosol profile initialized to increase linearly from zero below $1250 \mathrm{~m}$ altitude up to $N_{\mathrm{a}}$, absorb $=5000 \mathrm{mg}^{-1}$ at $1300 \mathrm{~m}$, maintain a uniform value up to $2800 \mathrm{~m}$, and then decrease to zero at $2850 \mathrm{~m}$ and above. Log-normal size distributions are specified for the sulfate and absorbing aerosol, with geometric mean radii of 0.05 and $0.12 \mu \mathrm{m}$ and geometric standard deviations of 1.2 and 1.3, respectively. The hygroscopicity parameter $\kappa$ (Petters and Kreidenweis, 2007) is set to 0.55 for ammonium sulfate and 0.2 for the absorbing aerosol. The size distribution for the absorbing aerosol is based on the measurements of J. M. Haywood et al. (2003) and the hygroscopicity (for aged biomass burning aerosol) from those of Englehart et al. (2012). The absorbing aerosol optical properties follow the approach of Ackerman et al. (2000), but here a soot core radius of $0.04 \mu \mathrm{m}$ is specified, resulting in a single scattering albedo (SSA) of 0.88 at wavelength $0.55 \mu \mathrm{m}$. The extinction coefficient within the absorbing aerosol layer is about $0.16 \mathrm{~km}^{-1}$ at $0.55 \mu \mathrm{m}$, consistent with the measurements reported by J. Haywood et al. (2003). The absorbing aerosol induces a heating rate of $\sim 2.6 \mathrm{~K} \mathrm{~d}^{-1}$ at noon and a diurnal-average heating rate $\sim 1.2 \mathrm{~K} \mathrm{~d}^{-1}$, consistent with observations exploited by Johnson et al. (2004) and Ackerman et al. (2000). The initial absorbing aerosol layer physical thickness of $1.5 \mathrm{~km}$ is loosely based on observations over the southeastern Atlantic by Chand et al. (2009), J. M. Haywood et al. (2003), and Labonne et al. (2007), who report a characteristic layer thickness over the Atlantic of 1-2 km. Sensitivities of the results to the assumed SSA of the absorbing aerosol and to their initial number concentration are briefly discussed.

To examine variations in bulk properties of the overlying aerosol layer, a further simulation is performed with the initial location $400 \mathrm{~m}$ higher, in which the model top is extended to $3.5 \mathrm{~km}$ and the column of overlying water vapor and ozone used for radiative fluxes adjusted accordingly. An additional baseline case with a $3.5 \mathrm{~km}$ deep grid was run for computing differences. Two other simulations consider a moist perturbation of $1 \mathrm{~g} \mathrm{~kg}^{-1}$ based on observations at St. Helena of equatorward outflow from the continental boundary layer (A15), scaled to the initial height of $N_{\mathrm{a}}$ absorb with and without absorbing aerosol. Finally, the impact of overlying ab- sorbing aerosol on heavily precipitating stratocumulus is examined by reducing $N_{\mathrm{a}}$, sulfate to $25 \mathrm{mg}^{-1}$. To isolate the microphysical effects of the overlying aerosol, a group of simulations with $N_{\mathrm{a} \text {, sulfate }}=150 \mathrm{mg}^{-1}$ is performed where the interaction of the absorbing aerosol with radiation is omitted. The aforementioned sedimentation and evaporation effects are examined by additional simulations that exclude cloud droplet sedimentation and that fix the cloud droplet relaxation timescale (instead of computing it per Eq. (A5) of Morrison and Grabowski, 2008). Semi-direct aerosol effects are dissected through simulations that restrict aerosol heating to the free troposphere (FT) or the PBL. Table 1 summarizes the setups for all simulations in the main text and its last column lists the figures in which each simulation appears.

Radiative forcings are computed from hourly time slices, which yield daily averages that differ negligibly from those using radiative fluxes updated every minute. We compute aerosol forcings following Ghan (2013), in which total forcing from a perturbation is calculated as the change in net downward radiative flux at TOA relative to the baseline: $\Delta F=F$ (perturbed) $-F$ (baseline). The sum of the indirect and semi-direct forcings from the absorbing aerosol is computed similarly but with the absorbing aerosol omitted when calculating $F$ (perturbed). The direct aerosol forcing is then derived by subtracting the sum of indirect and semi-direct forcings from the total forcing.

For the sake of comparison with Y15, in one instance we also compute cloud radiative forcing as the difference of net downward radiative fluxes at TOA with and without cloud: $F$ (all sky) $-F$ (clear sky). The difference between $\Delta F$ and the aerosol-induced change in cloud radiative forcing is the direct aerosol forcing for clear sky: $\triangle \mathrm{CRF}=$ $\Delta F-\Delta F$ (clear sky). The enhancement of aerosol absorption associated with SW reflection by an underlying cloud layer, which tends toward a positive forcing (e.g., Chand et al., 2009) and is implicitly included in $\Delta F$, is offset in $\Delta$ CRF by the subtraction of a direct forcing that tends to be more negative here, because the ocean surface is less reflective than the cloud layer. Subtraction of a negative direct forcing thereby yields a $\triangle \mathrm{CRF}$ that tends to be more positive than total forcing $\Delta F$.

In all forcing calculations for this study, net LW fluxes at TOA are scaled from net LW fluxes at the top of the model domain using $F_{\mathrm{TOA}}=2.627 F_{3.2 \mathrm{~km}}+0.0054 F_{3.2 \mathrm{~km}}^{2}$ for the $3.2 \mathrm{~km}$ deep grid, and using $F_{\mathrm{TOA}}=2.469 F_{3.5} \mathrm{~km}+$ $0.0046 F_{3.5 \mathrm{~km}}^{2}$ for the $3.5 \mathrm{~km}$ deep grid. These correlations were derived from the baseline case run on a $40 \mathrm{~km}$ deep grid, with root mean square (RMS) errors of 0.3 and $0.2 \mathrm{Wm}^{-2}$ on the shallower grids, with biases of less than $0.001 \mathrm{~W} \mathrm{~m}^{-2}$. No TOA corrections for SW fluxes are made because the radiative transfer scheme (Toon et al., 1989) provides accurate TOA fluxes by treating Rayleigh scattering in the overlying atmosphere. 


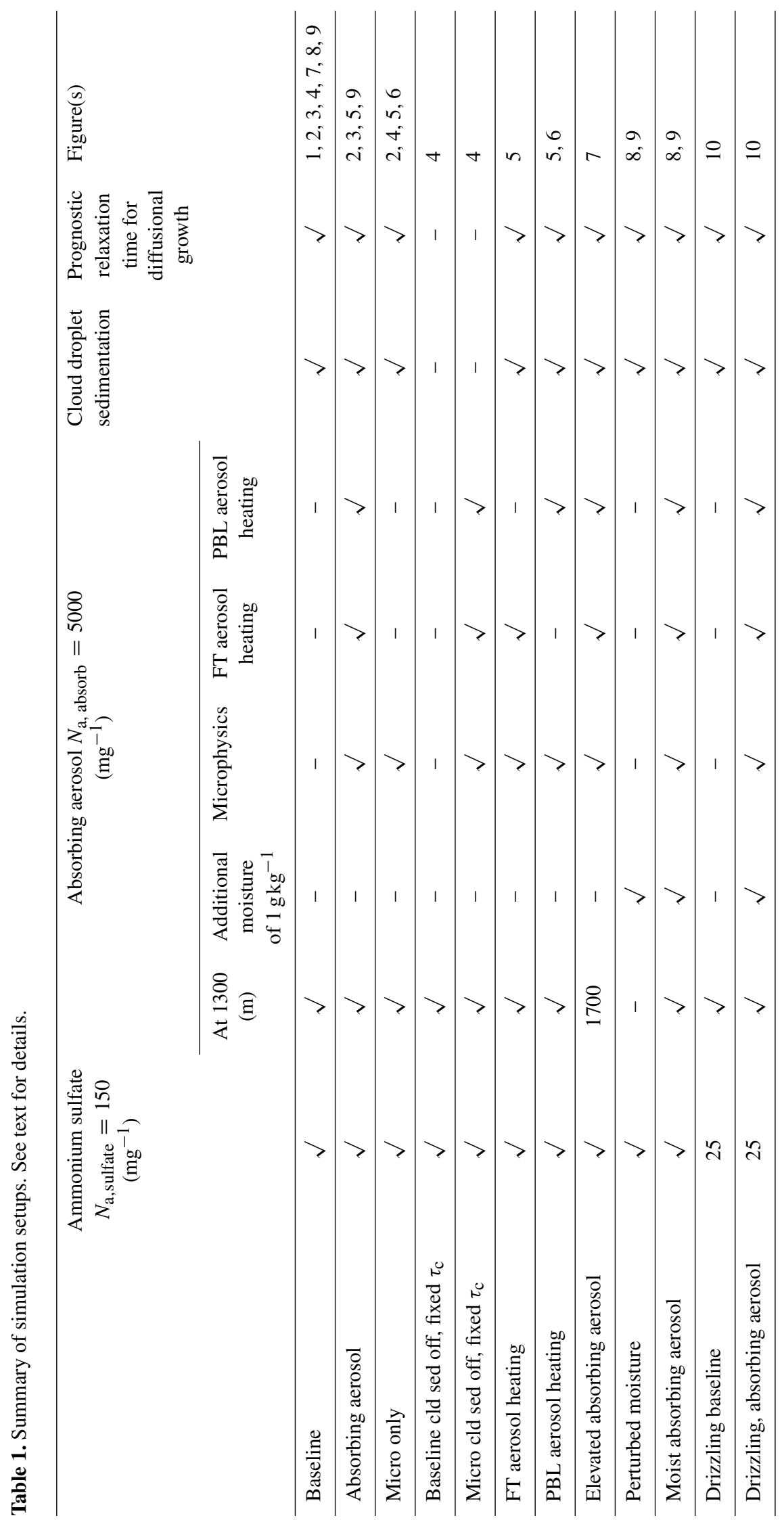



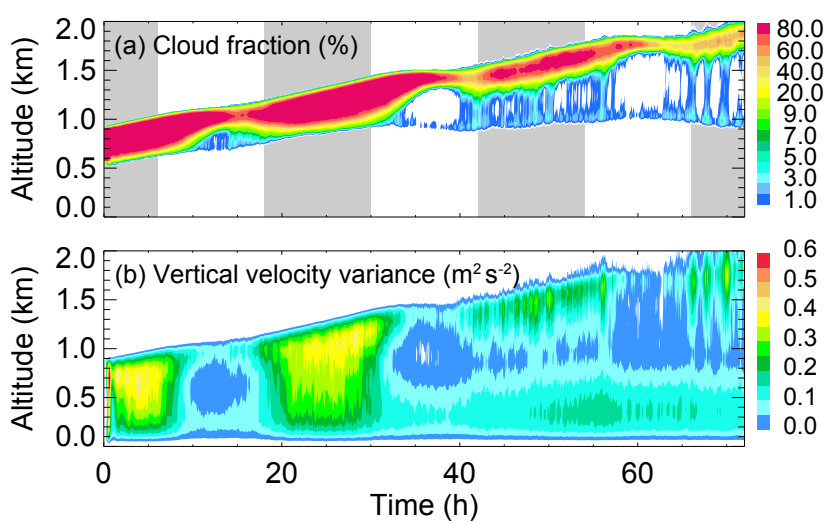

Figure 1. Evolution of horizontal average profiles of (a) cloud fraction (defined by a cloud water mixing ratio threshold of $0.01 \mathrm{~g} \mathrm{~kg}^{-1}$ ) and (b) vertical velocity variance for the lightly drizzling baseline case $\left(N_{\mathrm{a} \text {, sulfate }}=150 \mathrm{mg}^{-1}\right)$. The simulation starts at midnight local time. Gray shading indicates nominal nightime (06:00 pm 06:00 am local time).

\section{Impacts on lightly drizzling SCT}

\subsection{Overview of SCT with and without absorbing aerosol layer}

Figures 1 and 2 illustrate the transition from a compact stratocumulus layer to more broken fields of cumulus as a response to increasing SST for the lightly drizzling baseline case $\left(N_{\mathrm{a} \text {, sulfate }}=150 \mathrm{mg}^{-1}, N_{\mathrm{c}} \sim 100 \mathrm{~cm}^{-3}\right)$. After $\sim 2 \mathrm{~h}$ of boundary layer turbulence spin-up in one member of the baseline ensemble (Fig. 1b), the PBL depth in general increases with SST and reaches $2 \mathrm{~km}$ at the end of day 3 (Fig. 1a). The thinning of the stratocumulus is observed in the afternoon of day 1 as solar heating offsets some of the LW cooling that drives PBL mixing, when vertical wind variance profiles show bimodal structure with a local minimum near cloud base ( $\sim 12 \mathrm{~h}$ in Fig. 1b). Convection revitalizes after sunset and deepens the stratocumulus, when the mean precipitation rate at cloud base peaks at $\sim 0.1 \mathrm{~mm} \mathrm{~d}^{-1}$ in the baseline ensemble (Fig. 2i). Starting around sunrise of day 2 $(\sim 30 \mathrm{~h})$, the PBL becomes continuously stratified, with a persistent cumulus layer developing under the stratocumulus (Fig. 1a). This stratification reduces the subsequent nocturnal recovery, and leads to further reduction in LWP (Fig. 2b) and cloudiness (Fig. 2c) after sunrise on day 3. Following Sandu and Stevens (2011) by defining the SCT as the time at which cloud cover (the fraction of columns with LWP $>10 \mathrm{~g} \mathrm{~m}^{-2}$ ) first decreases to half of its initial value, the transition in the baseline case is at $\sim 62 \mathrm{~h}$.

When incorporating an overlying absorbing aerosol layer, the clouds and PBL evolve in a notably different way with an evident radiative impact (Figs. 2 and 3; Table 2). $N_{\mathrm{c}}$ increases gradually after the bottom of the ramp of subsiding aerosol contacts the deepening PBL at $\sim 15 \mathrm{~h}$ (Fig. 2a). The

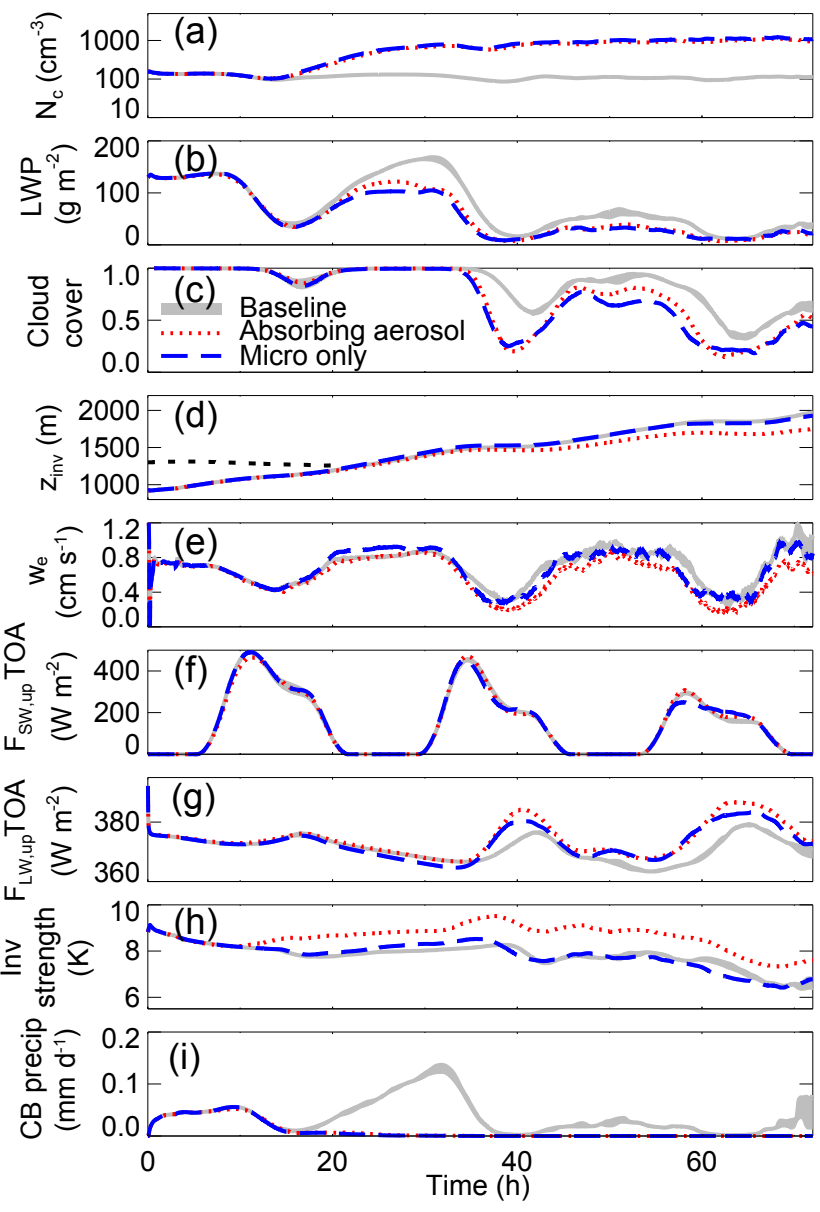

Figure 2. Evolution of domain averages of (a) cloud droplet number concentration $\left(N_{\mathrm{c}}\right.$ average weighted by cloud water mixing ratio), (b) liquid water path (LWP), (c) cloud cover (columns with LWP $>10 \mathrm{~g} \mathrm{~m}^{-2}$ ), (d) inversion height (height of maximum potential temperature gradient), (e) entrainment rate (difference of inversion height tendency and subsidence rate at inversion height), (f) upwelling shortwave (SW) and (g) longwave (LW) radiative fluxes at TOA, (h) inversion strength $(\Delta T$ across inversion defined as the vertical extent with continuous positive temperature gradient), and (i) precipitation rate at cloud base (mean over cloudy columns of lowermost height where the cloud water mixing ratio exceeds $0.01 \mathrm{~g} \mathrm{~kg}^{-1}$ ). Results shown as lagged $3 \mathrm{~h}$ running averages to smooth entrainment rates. Range of the three-member lightly drizzling baseline ensemble $\left(N_{\mathrm{a} \text {, sulfate }}=150 \mathrm{mg}^{-1}\right)$ in gray. Results with the absorbing aerosol layer shown as red dotted line. Results with the aerosol layer excluding radiative interaction shown as blue dashed line. The black dotted line in (d) indicates the base of the absorbing aerosol layer (lowest height where $N_{\mathrm{a}}$ absorb is full strength) before contacting the boundary layer.

full strength of the aerosol layer reaches the PBL at $\sim 20 \mathrm{~h}$ (Fig. 2d). Before the subsiding aerosol layer contacts the deepening PBL, absorption of SW radiation in the aerosol layer dominates the radiative impact and reduces the diurnalaverage upwelling SW radiative fluxes at TOA by $\sim 7 \mathrm{~W} \mathrm{~m}^{-2}$ 
Table 2. Diurnal-average direct forcing, indirect plus semi-direct forcing, and sum of forcings (in $\mathrm{W} \mathrm{m}^{-2}$ ) from the overlying absorbing aerosol for the lightly drizzling case $\left(N_{\mathrm{a} \text {, sulfate }}=150 \mathrm{mg}^{-1}\right)$ on day $1(0-24 \mathrm{~h})$, day $2(24-48 \mathrm{~h})$, and day $3(48-72 \mathrm{~h})$. The 3 -day average radiative forcing is indicated in the last row. Boldface indicates results exceeding the uncertainty range derived from the baseline ensemble spread.

\begin{tabular}{|c|c|c|c|c|c|c|c|}
\hline & \multicolumn{3}{|c|}{ Direct forcing } & \multicolumn{3}{|c|}{$\begin{array}{c}\text { Indirect }+ \\
\text { semi-direct forcing }\end{array}$} & \multirow{2}{*}{$\begin{array}{r}\text { Total } \\
\mathrm{SW}+\mathrm{LW}\end{array}$} \\
\hline & SW & LW & $\mathrm{SW}+\mathrm{LW}$ & SW & LW & $\mathrm{SW}+\mathrm{LW}$ & \\
\hline Day 1 & 7.3 & -0.3 & 7.0 & -1.6 & -0.2 & -1.8 & 5.2 \\
\hline Day 2 & 0.8 & -0.2 & 0.6 & -0.5 & -2.6 & -3.1 & -2.5 \\
\hline Day 3 & -3.7 & 0.0 & -3.7 & -1.2 & -6.0 & -7.2 & -10.9 \\
\hline Mean & 1.5 & -0.2 & 1.3 & -1.1 & -2.9 & -4.0 & -2.7 \\
\hline
\end{tabular}

on day 1 (Fig. 2f, Table 2). This SW absorption by the aerosol layer decreases with time when the cloud field is more broken, since less upwelling SW radiation is reflected back into the layer (cf. Chand et al., 2009) and when it is mixed below cloud, where less SW radiation reaches the absorbing aerosol. On day 3, SW absorption is overcome by scattering, resulting in a negative direct forcing (Table 2).

As the absorbing layer approaches the PBL, the inversion strengthens (Fig. 2h), which would tend to slow entrainment. However, as the layer makes contact with the clouds, the entrained aerosol activates cloud droplets and leads to a pronounced increase in $N_{\mathrm{c}}$, which is ultimately increased by a factor of $\sim 10$ over the baseline to $\sim 1000 \mathrm{~cm}^{-3}$ (Fig. 2a). The increased $N_{\mathrm{c}}$ acts to accelerate entrainment through the sedimentation and evaporation effects, and opposes but does not overcome the opposing tendency from the strengthening of the inversion (Fig. 2d and e). The entrainment of warmer air with less RH leads to a reduction of LWP (Fig. 2b) and cloud cover (Fig. 2c), hastening and enhancing the SCT on day 2 (Fig. 2c). This SCT acceleration is opposite to Y15, who found that entrained absorbing aerosol delays the SCT and leads to overcast conditions during the second half of $72 \mathrm{~h}$ simulations. As a result of substantially reduced LWP, here the overlying absorbing aerosol case yields a positive change in TOA SW CRF relative to the baseline during the 3-day simulation (Table 3). The daytime average SW $\triangle \mathrm{CRF}$ after the soot contacts the PBL is $9.3 \mathrm{~W} \mathrm{~m}^{-2}$, opposite in sign to that of Y15. Meanwhile, the negative LW contributions to $\triangle \mathrm{CRF}$ are enhanced during the transition, and overcome the positive SW $\triangle \mathrm{CRF}$ on day 3. As explained further below, such LW contributions result from microphysical and heating effects. While such LW forcings are often ignored when considering aerosol impacts on low-lying clouds, much of the subtropical and tropical atmosphere is not particularly moist, with column water vapor of less than $30 \mathrm{~mm}$ (cf. Lindstrot et al., 2014) as it is here (initial and final values, respectively, of about 25 and $30 \mathrm{~mm}$ ), allowing changes in low-level clouds to impact LW fluxes at TOA.
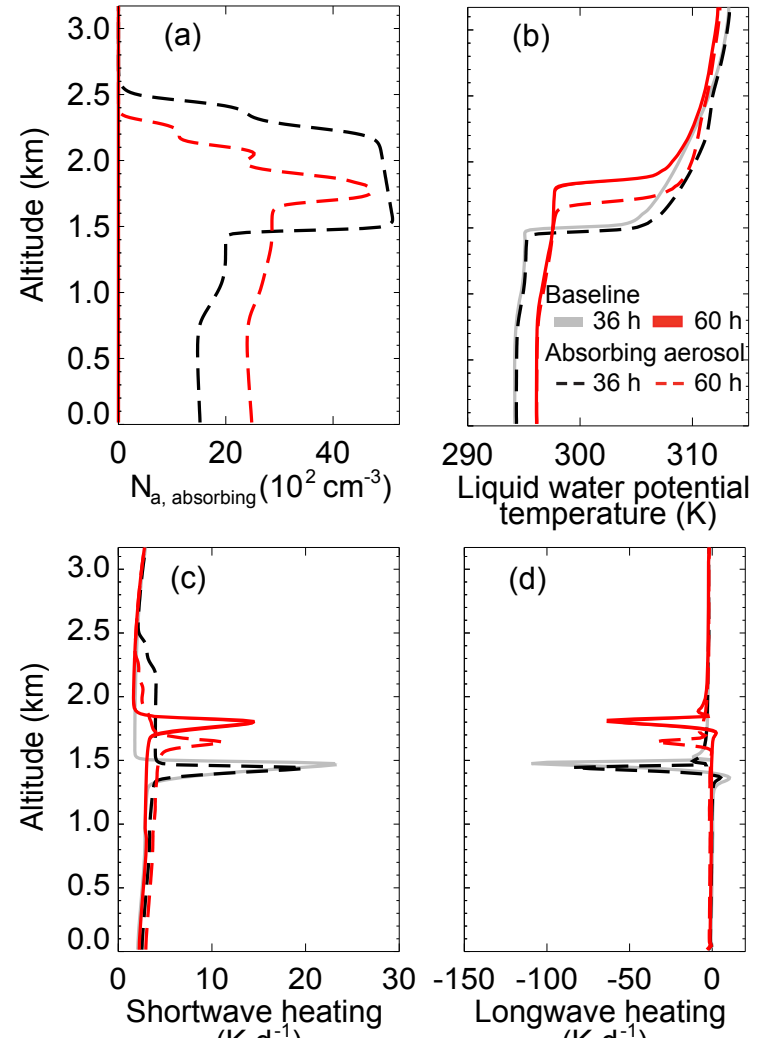

$\left(\mathrm{K} \mathrm{d}^{-1}\right)$

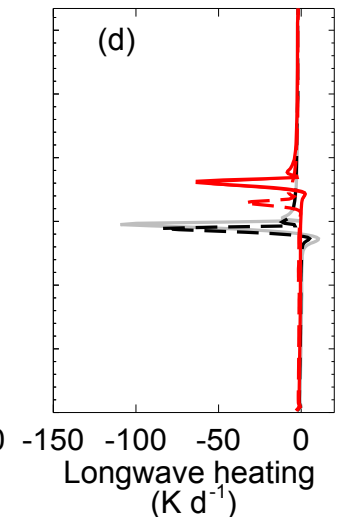

Figure 3. Horizontally averaged profiles of (a) the number concentration of absorbing aerosol, (b) liquid water potential temperature, (c) SW heating rate, and (d) LW heating rate at the 36th hour (gray solid line) and the 60th hour (red solid line) for the lightly drizzling baseline ensemble $\left(N_{\mathrm{a}}\right.$, sulfate $\left.=150 \mathrm{mg}^{-1}\right)$ and with overlying absorbing aerosol (dashed line).

\subsection{Microphysical effects}

The microphysical effects of the subsiding aerosol are isolated by omitting aerosol heating and comparing them to the same baseline (Fig. 4). The substantial increase in $N_{\mathrm{c}}$ as a result of the entrained aerosol is seen to largely explain overall 


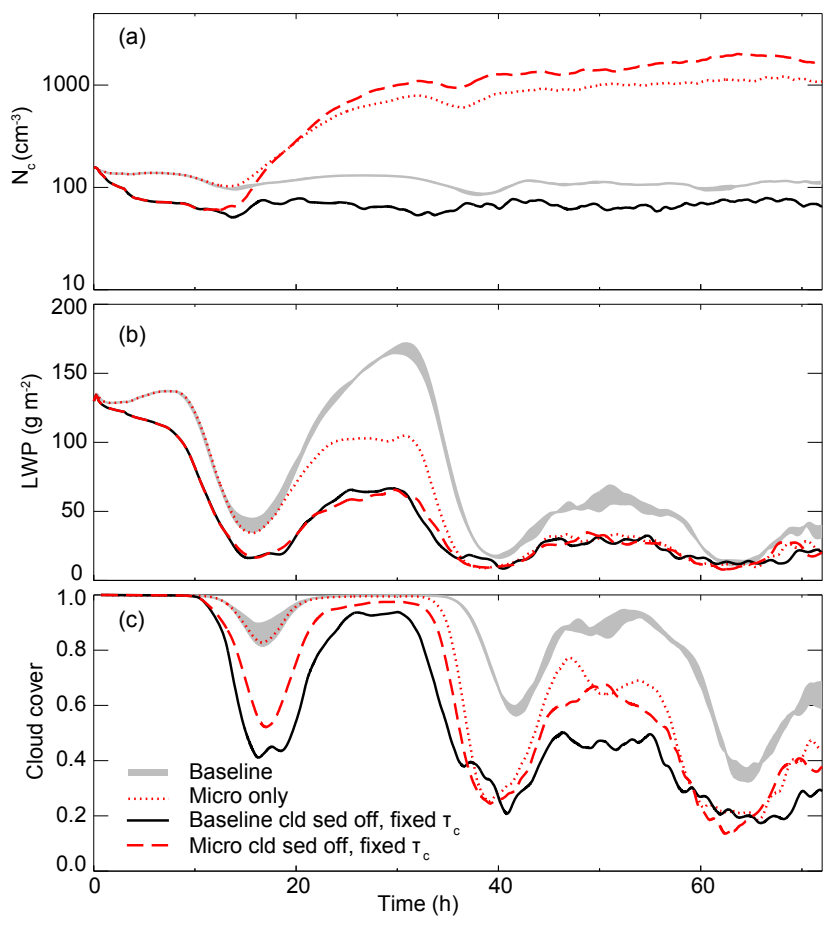

Figure 4. As in Fig. 2 with the baseline in gray and with overlying aerosol that does not affect radiation shown with dotted red line. Baseline and overlying aerosol cases in the absence of clouddroplet sedimentation and with a fixed relaxation time for diffusional growth of cloud droplets $\left(\tau_{\mathrm{c}}\right)$ are shown with black solid and red dashed lines, respectively.

reductions of both LWP and cloud cover relative to the baseline simulation, leading to a hastened SCT. Such disparity in LWP and cloud cover with and without entrained aerosol is reduced when either the sedimentation effect is excluded (by omitting cloud droplet sedimentation from both simulations) or when the evaporation effect is excluded (by fixing the cloud droplet diffusional growth relaxation time in both simulations). When both effects are excluded, simulations with and without entraining aerosol exhibit negligible differences in LWP and a reversed difference in cloud cover. Thus, the hastened SCT from absorbing aerosol in DHARMA simulations can be attributed primarily to the microphysical effects of increased $N_{\mathrm{c}}$, specifically via sedimentation and evaporation effects.

With the semi-direct effect now excluded by omitting aerosol absorption, the indirect forcing is isolated (Table 4). Despite the substantial reduction in cloud cover, the entrained aerosol results in only a modest positive aerosol indirect forcing on day 2 and a negative forcing on day 3 (Table 4). The negative forcing is driven by a negative LW forcing, as a result of more broken clouds and emission from a warmer SST, and by a significant Twomey effect, which does not fully offset the opposed, comparable SW forcing induced by the sedimentation and evaporation effects (Table 5).
Table 3. Diurnal-average changes in cloud radiative forcings ( $\triangle \mathrm{CRF}$; in $\mathrm{W} \mathrm{m}^{-2}$ ) for the overlying absorbing aerosol case relative to the lightly drizzling baseline case $\left(N_{\mathrm{a}}\right.$, sulfate $\left.=150 \mathrm{mg}^{-1}\right)$. Conventions as in Table 2.

\begin{tabular}{lrrr}
\hline & \multicolumn{3}{c}{$\Delta$ CRF TOA $\left(\mathrm{W} \mathrm{m}^{-2}\right)$} \\
\cline { 2 - 4 } & SW & LW & $\mathrm{SW}+\mathrm{LW}$ \\
\hline Day 1 & $\mathbf{1 4 . 6}$ & -0.2 & $\mathbf{1 4 . 4}$ \\
Day 2 & $\mathbf{8 . 5}$ & $\mathbf{- 2 . 0}$ & $\mathbf{6 . 5}$ \\
Day 3 & $\mathbf{2 . 3}$ & $\mathbf{- 4 . 8}$ & $\mathbf{- 2 . 5}$ \\
\hline Mean & $\mathbf{8 . 4}$ & $\mathbf{- 2 . 3}$ & $\mathbf{6 . 1}$ \\
\hline
\end{tabular}

Table 4. Indirect forcing of absorbing aerosol, computed as the diurnal-average difference in radiative fluxes at TOA (in $\mathrm{Wm}^{-2}$ ) of the simulation with absorbing aerosol not directly affecting radiation, relative to the lightly drizzling baseline case $\left(N_{\mathrm{a} \text {, sulfate }}=\right.$ $150 \mathrm{mg}^{-1}$ ). Conventions as in Table 2 .

\begin{tabular}{lrrr}
\hline & \multicolumn{3}{c}{ Indirect forcing } \\
\cline { 2 - 4 } & SW & LW & SW + LW \\
\hline Day 1 & -0.7 & $\mathbf{0 . 4}$ & -0.3 \\
Day 2 & $\mathbf{2 . 5}$ & $\mathbf{- 0 . 9}$ & $\mathbf{1 . 6}$ \\
Day 3 & $\mathbf{1 . 2}$ & $\mathbf{- 5 . 2}$ & $\mathbf{- 4 . 0}$ \\
\hline Mean & 1.0 & $\mathbf{- 1 . 9}$ & -0.9 \\
\hline
\end{tabular}

\subsection{Semi-direct effects}

Next we isolate the semi-direct effects of aerosol heating by considering aerosol absorption in the FT and PBL and throughout the atmosphere and by comparing it to the preceding case that only included microphysical effects of the entrained aerosol layer. By doing so we build upon the results of the previous section, effectively evaluating the semidirect effect in the presence of microphysical effects rather than in their absence. As seen in Fig. 5, aerosol heating in the FT substantially strengthens the PBL inversion as the aerosol layer approaches the PBL (Fig. 5e), enhancing LWP and cloud cover (Figs. 5b and $5 \mathrm{c}$ ) by inhibiting entrainment (Fig. 5d). The increase in LWP delays and weakens the SCT, contributing to a negative SW forcing (Table 6). In contrast, aerosol heating in the PBL reduces LWP and cloud cover in the daytime (Fig. 5b and c) by lowering the relative humidity in the PBL and by stabilizing the PBL (Fig. 6a), hampering the moisture supply from the surface (Fig. 6b). The reduction in cloud amount amplifies the diurnal contrast of cloud fraction and hastens the SCT, resulting in a positive SW forcing (Table 6).

The competing effects of aerosol heating in the FT versus the PBL serve to increase cloud water at night while reducing it during daytime, enhancing its diurnal cycle (Fig. 5c). Diurnally averaged, the effect of aerosol heating in the FT is dom- 
Table 5. Schematic of SW and LW radiative responses (changes in net downward fluxes at TOA) to microphysical and thermal effects of the initially overlying absorbing aerosol layer. $N_{\mathrm{c}}$ refer to clouddroplet concentrations, $\mathrm{CF}$ cloud fraction, and $Z_{\mathrm{i}}$ inversion height. Plus signs refer to positive responses, negative signs to negative responses, and zeros to negligible or absent responses.

\begin{tabular}{|c|c|c|c|}
\hline & & SW & LW \\
\hline \multicolumn{4}{|c|}{ Microphysical effects } \\
\hline Twomey effect & $N_{\mathrm{c}} \uparrow$ & - & 0 \\
\hline $\begin{array}{l}\text { Cloud-droplet sedim } \\
\text { evaporation } \uparrow\end{array}$ & $\mathrm{CF} \downarrow$ & + & - \\
\hline \multicolumn{4}{|c|}{ FT aerosol heating } \\
\hline Inversion strength $\uparrow$ & $\begin{array}{l}\mathrm{CF} \uparrow \\
Z_{\mathrm{i}} \downarrow\end{array}$ & $\overline{-}$ & $\begin{array}{l}+ \\
-\end{array}$ \\
\hline \multicolumn{4}{|c|}{ PBL aerosol heating } \\
\hline RH decrease & $\begin{array}{l}\mathrm{CF} \downarrow \\
Z_{\mathrm{i}} \downarrow\end{array}$ & $\begin{array}{l}+ \\
0\end{array}$ & - \\
\hline \multicolumn{4}{|c|}{ Other } \\
\hline Warming SST & & 0 & - \\
\hline
\end{tabular}
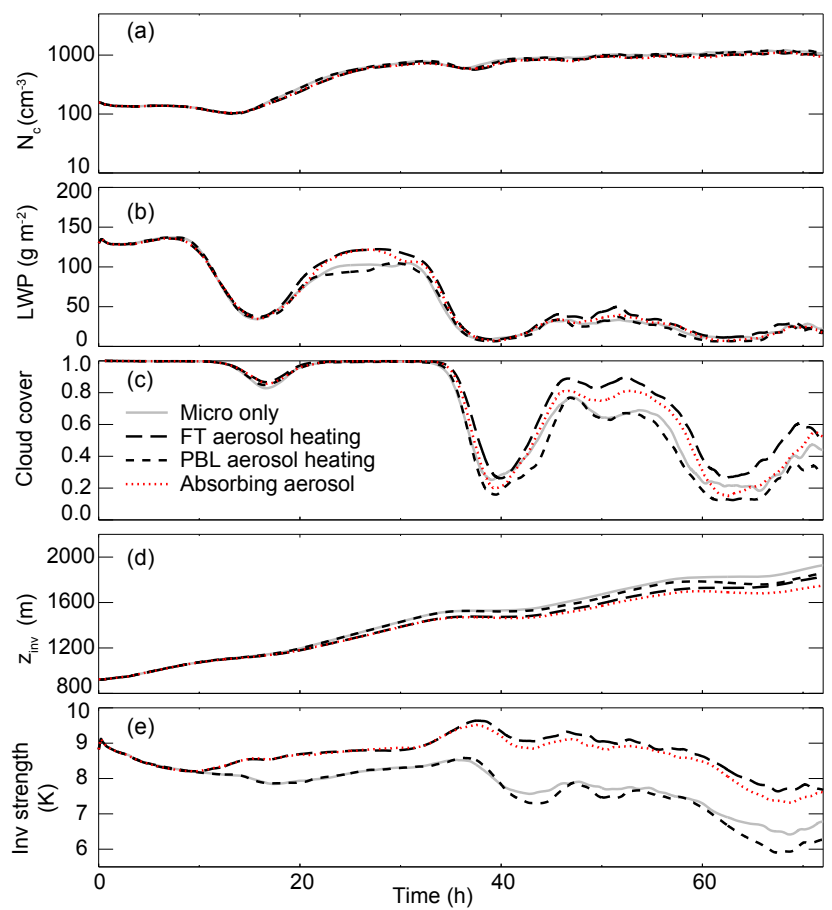

Figure 5. As in Fig. 2. All cases include initially overlying absorbing aerosol and allow them to act as CCN. For gray solid line the aerosol does not affect radiation. For long and short dashed lines, the aerosol affects radiation only in the free troposphere (FT) and planetary boundary layer (PBL), respectively. For red dotted line there are no restrictions on aerosol affecting radiation, as in Fig. 2.
Table 6. Semi-direct forcing of absorbing aerosol, computed as the diurnal-average difference in radiative fluxes at TOA $\left(\right.$ in $\mathrm{W} \mathrm{m}^{-2}$ ) of simulations with aerosol heating restricted to the FT and PBL, or not restricted relative to the simulation without aerosol heating. All simulations allow the absorbing aerosol to act as CCN. Boldface indicates results exceeding the uncertainty range derived from the spread of the lightly drizzling baseline ensemble.

\begin{tabular}{lrrrr}
\hline & & \multicolumn{3}{c}{ Semi-direct forcing } \\
\cline { 3 - 5 } & & SW & LW & SW + LW \\
\hline FT aerosol & Day 1 & -1.9 & $\mathbf{- 0 . 6}$ & -2.5 \\
heating & Day 2 & $\mathbf{- 1 2 . 4}$ & $\mathbf{- 0 . 2}$ & $\mathbf{- 1 2 . 6}$ \\
& Day 3 & $\mathbf{- 2 0 . 6}$ & $\mathbf{2 . 7}$ & $\mathbf{- 1 7 . 9}$ \\
\hline PBL aerosol & Day 1 & -1.3 & 0.0 & -1.3 \\
heating & Day 2 & $\mathbf{5 . 5}$ & $\mathbf{- 1 . 2}$ & $\mathbf{4 . 3}$ \\
& Day 3 & $\mathbf{1 5 . 2}$ & $\mathbf{- 3 . 2}$ & $\mathbf{1 2 . 0}$ \\
\hline FT, PBL aerosol & Day 1 & -0.9 & $\mathbf{- 0 . 6}$ & $\mathbf{- 1 . 5}$ \\
heating & Day 2 & $\mathbf{- 3 . 0}$ & $\mathbf{- 1 . 7}$ & $\mathbf{- 4 . 7}$ \\
& Day 3 & $\mathbf{- 2 . 4}$ & $\mathbf{- 0 . 8}$ & $\mathbf{- 3 . 2}$ \\
& Mean & $\mathbf{- 2 . 1}$ & $\mathbf{- 1 . 0}$ & $\mathbf{- 3 . 1}$ \\
\hline
\end{tabular}
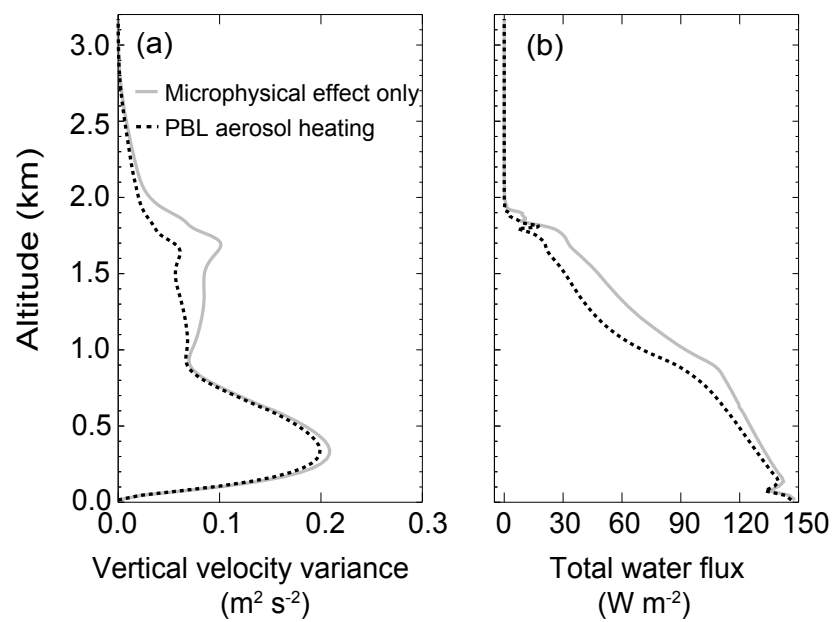

Figure 6. Horizontally averaged profiles of (a) vertical velocity variance and (b) total water flux averaged over 10:00 to 14:00 local time on day 3 for simulations with (gray solid line) and without (black dotted line) absorbing aerosol affecting radiation in the PBL. Both simulations include microphysical effects of the entrained aerosol layer.

inant and leads to increased LWP and cloud cover and therefore a negative average SW forcing during the 3-day transition (Fig. 5c, Table 6). The net SW forcing is smaller than the sum of the SW forcings via individual FT and PBL aerosol heating, indicating interactions that reduce the component forcings when combined (Table 6). Specifically, aerosol absorption in the FT slightly reduces the SW flux available for aerosol heating in the PBL, while the greater cloud breakup in the daytime reduces the reflected upwelling SW flux, in 
turn reducing aerosol heating in the FT. The combined effects also result in LWP and cloud cover intermediate between the results when considered separately (Fig. 5).

In contrast to the counteracting impacts on cloud water, FT and PBL aerosol heating both inhibit entrainment by intensifying the inversion and by stratifying the PBL (Fig. 5c). The reduced PBL depth corresponds to warmer cloud tops, which emit more LW radiation upwards, leading to net negative LW forcing on days 2 and 3 despite an increase in LWP and cloud cover (Table 6).

\subsection{Combined effects}

Comparing Tables 2, 4, and 6 it is seen that net SW forcing is weakened with all effects included because the increased LWP from aerosol heating compensates for some of the LWP loss from microphysical effects on day 2 (Table 2, Fig. 6), and the direct aerosol heating on day 1 greatly counteracts the negative radiative forcings after the aerosol layer contacts the PBL. As a result, the mean SW impact over the 3-day transition nearly vanishes (Table 2 ). The LW radiative forcing, however, accumulates and strengthens during the transition, and therefore is the dominant contributor to a negative average forcing during the transition (Table 2). In a nutshell, although the subsiding aerosol layer directly absorbs solar radiation and breaks up the clouds faster and more thoroughly, the CCN source serves to distribute cloud water over a greater number of drops, increasing the optical thickness of the remaining clouds but at a lower altitude, increasing both upwelling SW and LW radiative fluxes, leading to a net negative forcing. We note that day 3 net SW forcing is only negative when the aerosol is absorbing $\left(-1.2 \mathrm{~W} \mathrm{~m}^{-2}\right.$ in Table 2); otherwise, the Twomey effect is not strong enough to counteract the reduction in cloud fraction, and day 3 net SW forcing is equally positive $\left(1.2 \mathrm{~W} \mathrm{~m}^{-2}\right.$ in Table 4$)$.

The study of the effects of absorbing aerosol on the SCT by Y15 considered only SW forcings, which seems sensible given that studies of semi-direct effects in stratocumulus (Johnson et al., 2004) and trade cumulus (Ackerman et al., 2000; Johnson, 2005) have found SW forcings to be dominant. However, here we find interaction of aerosol and clouds in response to multiple effects leads to small net SW forcings: for example, positive SW forcing from PBL aerosol heating and microphysical effects on dynamics offset negative SW forcing from FT aerosol heating and the Twomey effect (Table 5). By contrast, the negative LW forcings from multiple effects (i.e., cloud water reduction and PBL deepening) work in the same direction and result in a substantial net LW forcing for the SCT.

Sensitivity tests with varying values of the SSA and initial number concentrations of the absorbing aerosol are summarized in Appendix A1. A decrease in SSA at $0.55 \mu \mathrm{m}$ wavelength from 0.88 to 0.71 hastens the SCT less but leads to a positive radiative forcing averaged over the 3 -day transition, attributable to direct absorption by the aerosol. A decrease

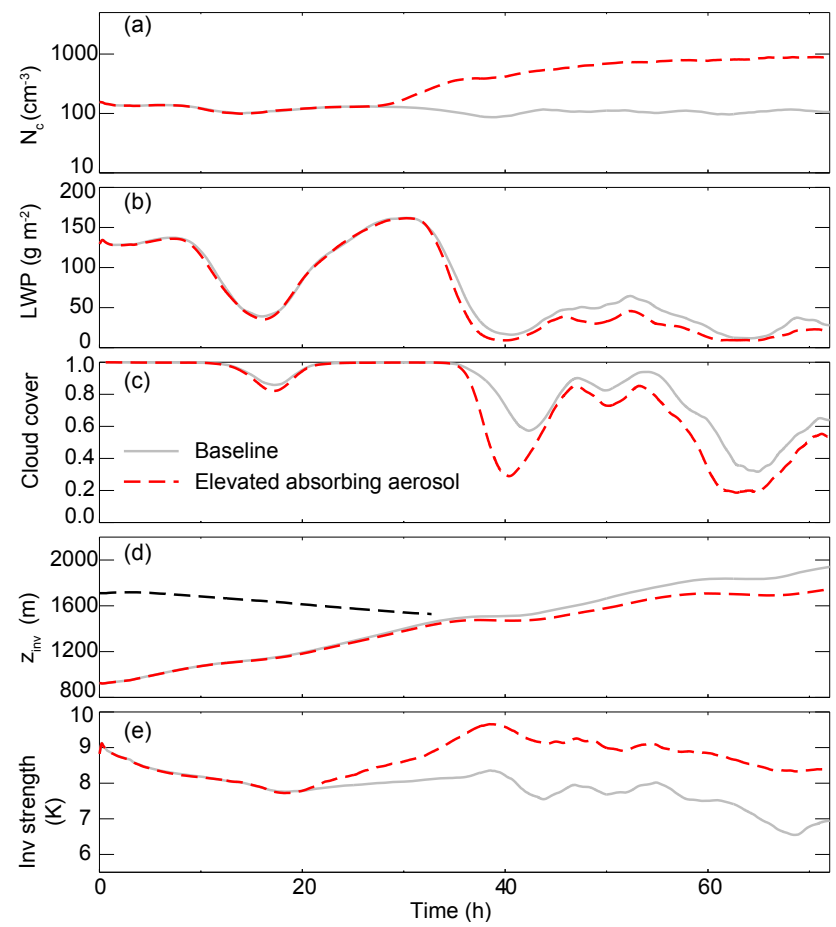

Figure 7. As in Fig. 2. The baseline with a $3.5 \mathrm{~km}$ deep grid $\left(N_{\mathrm{a}, \text { sulfate }}=150 \mathrm{mg}^{-1}\right)$ shown as gray solid line. Results with the aerosol layer initially $400 \mathrm{~m}$ higher shown as red dashed line, with the corresponding aerosol layer base shown as black dashed line in (d).

in the initial number concentration for the overlying aerosol with an SSA of 0.88 serves to weaken its negative 3-day average radiative forcing.

\section{Variations in bulk properties of overlying aerosol layer}

\subsection{Higher initial elevation}

Increasing the initial height of the base of the aerosol layer by $400 \mathrm{~m}$ delays contact with the PBL by about half a day (Fig. 7a). The delayed contact reduces the entrainment of aerosol relative to the case with the layer starting lower, thereby hindering cloud breakup (comparing Figs. $7 \mathrm{~b}-\mathrm{c}$ with $2 \mathrm{~b}-\mathrm{c}$ ). The enhanced cloud amount leads to a much greater SW negative forcing on days 2 and 3, despite greater direct absorption owing to the extended duration of the aerosol aloft on day 2 (Tables 2 and 7). The delayed contact also provides for a longer duration of heating aloft and thereby a stronger inversion on day 3 (Fig. 7e), favoring maintenance of the clouds and thus a negative SW forcing. Despite increased LWP and cloud cover, the SCT with a higher elevated aerosol layer is still hastened relative to the baseline (Fig. 7). The greater negative SW forcing of the more elevated aerosol layer after its contact with the PBL ul- 
Table 7. As in Table 2 but with the absorbing aerosol layer initially located $400 \mathrm{~m}$ higher. Boldface indicates results exceeding the uncertainty range derived from the spread of the lightly drizzling baseline ensemble.

\begin{tabular}{|c|c|c|c|c|c|c|c|}
\hline & \multicolumn{3}{|c|}{ Direct forcing } & \multicolumn{3}{|c|}{$\begin{array}{c}\text { Indirect }+ \\
\text { semi-direct forcing }\end{array}$} & \multirow[b]{2}{*}{$\mathrm{SW}+\mathrm{LW}$} \\
\hline & SW & LW & $\mathrm{SW}+\mathrm{LW}$ & SW & LW & $\mathrm{SW}+\mathrm{LW}$ & \\
\hline Day 1 & 6.5 & -0.2 & 6.3 & 4.2 & -0.6 & 3.6 & 9.9 \\
\hline Day 2 & 3.8 & -0.3 & 3.5 & -11.2 & -1.9 & -13.1 & -9.6 \\
\hline Day 3 & -3.0 & -0.1 & -3.1 & $-\mathbf{5 . 0}$ & -4.7 & -9.7 & -12.8 \\
\hline Mean & 2.4 & -0.2 & 2.2 & -4.0 & -2.4 & -6.4 & -4.2 \\
\hline
\end{tabular}

Table 8. As in Table 2 but for the response of a lightly drizzling baseline to a perturbation of moisture instead of aerosol. Boldface indicates results exceeding the uncertainty range derived from the spread of the lightly drizzling baseline ensemble.

\begin{tabular}{lrrr}
\hline & \multicolumn{2}{c}{ Net flux change at TOA $\left(\mathrm{W} \mathrm{m}^{-2}\right)$} \\
\cline { 2 - 4 } & $\mathrm{SW}$ & $\mathrm{LW}$ & $\mathrm{SW}+\mathrm{LW}$ \\
\hline Day 1 & $\mathbf{1 1 . 6}$ & $\mathbf{- 1 . 3}$ & $\mathbf{1 0 . 3}$ \\
Day 2 & $\mathbf{- 1 7 . 5}$ & $\mathbf{- 0 . 2}$ & $\mathbf{- 1 7 . 7}$ \\
Day 3 & $\mathbf{- 9 . 9}$ & $\mathbf{2 . 4}$ & $\mathbf{- 7 . 2}$ \\
\hline Mean & $\mathbf{- 5 . 2}$ & $\mathbf{0 . 3}$ & $\mathbf{- 4 . 9}$ \\
\hline
\end{tabular}

timately leads to a more negative 3 -day mean radiative forcing to the case with the layer starting lower (Tables 2 and 7).

\subsection{Additional moisture}

Given that observations indicate that biomass burning plumes over Namibian stratocumulus are moister than the surrounding air (A15), next we additionally consider a moisture perturbation relative to the baseline. As seen in Fig. 8, the moisture induces additional SW heating and LW cooling (Fig. 8a, b), with the latter dominating. The net cooling offsets some SW heating especially near the top of the moist layer (Fig. 8c). Before the moist layer contacts the PBL, the additional downward LW radiative fluxes from its moisture serve to reduce cloud-top radiative cooling and thereby drive weaker PBL mixing that results in a more broken cloud field relative to the dry case (Fig. 9c). Reduced LWP diminishes upwelling SW radiative fluxes, enhancing the positive SW forcing on day 1 (Table 8). After the moist layer contacts the PBL, the entrained moist air leads to greater LWP and cloud cover than for the baseline, despite a weaker inversion (Figs. 8c and 9e). The increased cloud water greatly increases the net outgoing SW flux at TOA on days 2 and 3 (Table 8), and delays the SCT relative to the dry baseline (Fig. 9b and c). The SW changes in TOA radiative fluxes are seen in Table 8 to dominate the LW changes.

When an absorbing aerosol is then added to the moist layer aloft, the SCT is faster and more pronounced relative to the
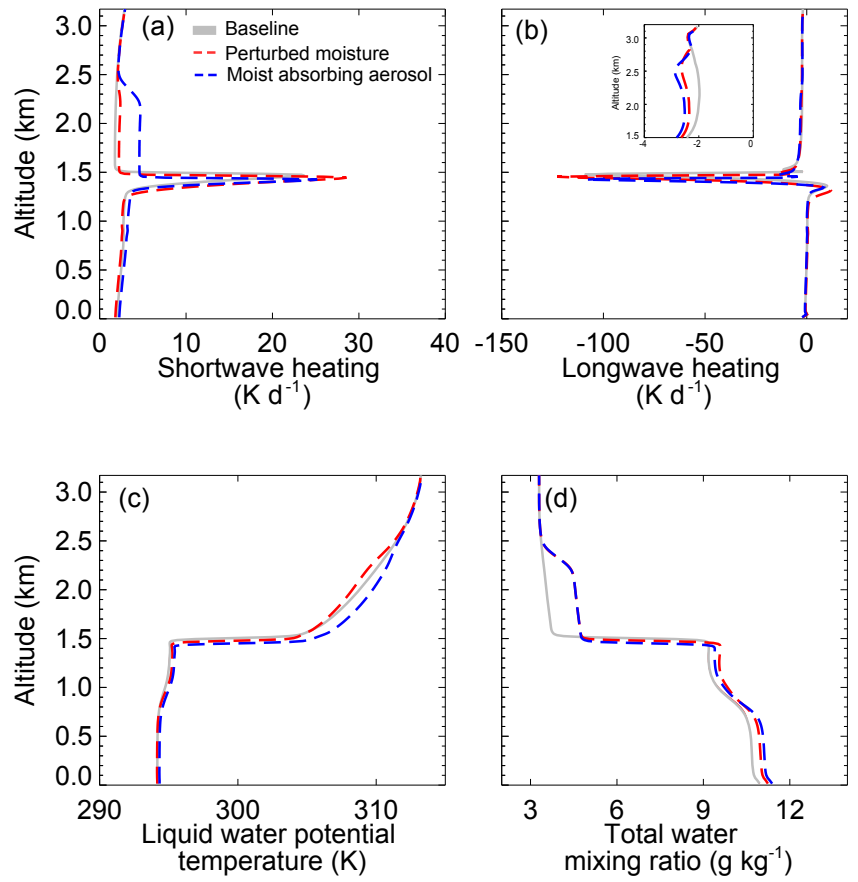

Figure 8. Horizontally averaged profiles of (a) SW heating rate, (b) LW heating rate, (c) liquid water potential temperature, and (d) total water mixing ratio averaged over hours 35-37 for the lightly drizzling baseline ensemble $\left(N_{\mathrm{a}}\right.$, sulfate $=150 \mathrm{mg}^{-1}$ ) (gray and black), perturbed moist case (red), and perturbed moist absorbing aerosol case (blue). The subpanel in (b) shows the diurnalaverage LW heating rate profile on day 1 from 1.5 to $3.2 \mathrm{~km}$.

case with only a moisture perturbation (Fig. 9c). Comparison of Tables 2 and 9 reveals that the LW forcings are comparable with and without the additional moisture, but the SW forcings induced by indirect and semi-direct effects are about $4 \mathrm{~W} \mathrm{~m}^{-2}$ greater on days 2 and 3 with the moisture aloft. A thicker cloud layer with greater cloud cover has more to lose, and the more dramatic reduction in cloud cover during daytime predominantly changes the SW forcing. During nighttime, however, cloud cover diminishes less as a result of the entrained moist air (Fig. 9c). The counteracting day and night impacts on cloud cover keep the PBL depth close to that in 
Table 9. As in Table 2 but for a lightly drizzling baseline with a moisture perturbation aloft. Boldface indicates results exceeding the uncertainty range derived from the spread of the lightly drizzling baseline ensemble.

\begin{tabular}{|c|c|c|c|c|c|c|c|}
\hline & \multicolumn{3}{|c|}{ Direct forcing } & \multicolumn{3}{|c|}{$\begin{array}{c}\text { Indirect }+ \\
\text { semi-direct forcing }\end{array}$} & \multirow[b]{2}{*}{$\mathrm{SW}+\mathrm{LW}$} \\
\hline & SW & LW & $\mathrm{SW}+\mathrm{LW}$ & SW & LW & $\mathrm{SW}+\mathrm{LW}$ & \\
\hline Day 1 & 6.1 & -0.2 & 5.9 & -1.5 & -0.3 & -1.8 & 4.1 \\
\hline Day 2 & 1.8 & -0.2 & 1.6 & 3.0 & -2.2 & 0.8 & 2.4 \\
\hline Day 3 & -3.5 & 0.0 & -3.6 & 2.8 & -6.8 & -4.0 & -7.6 \\
\hline Mean & 1.5 & -0.1 & 1.4 & 1.4 & -3.1 & -1.7 & -0.3 \\
\hline
\end{tabular}

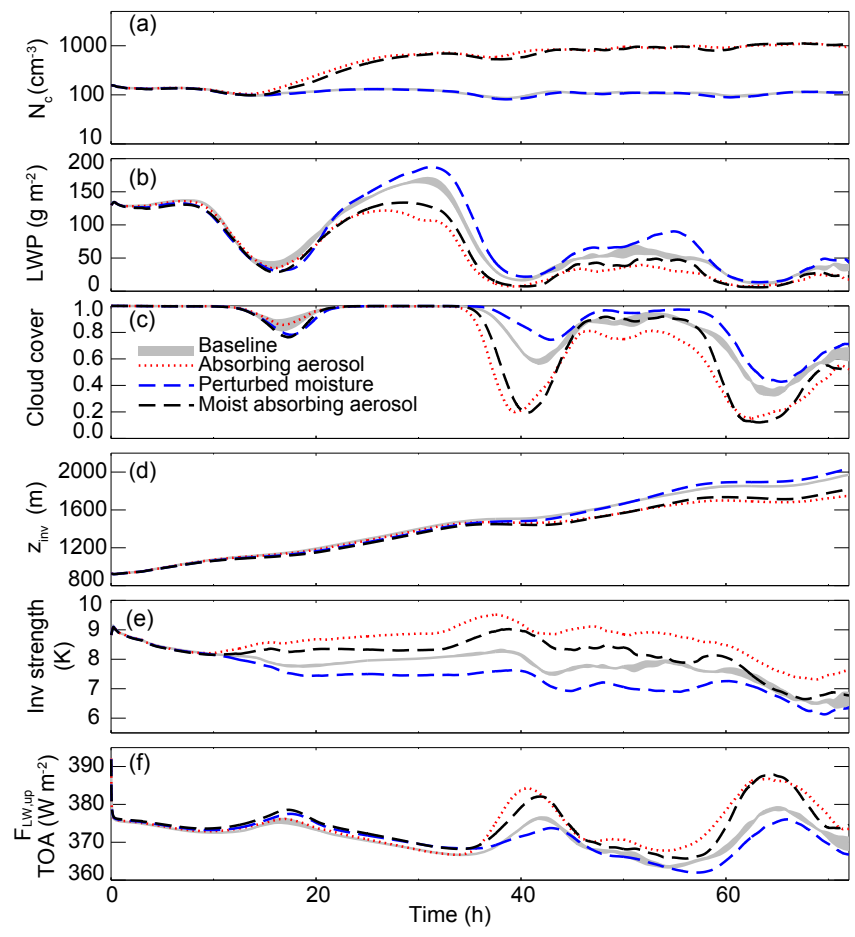

Figure 9. As in Fig. 2. Range of the three-member lightly drizzling baseline ensemble $\left(N_{\mathrm{a}}\right.$, sulfate $\left.=150 \mathrm{mg}^{-1}\right)$ shown in gray. Results with an absorbing aerosol layer shown as red dotted line. Baseline with moist layer aloft shown as blue dashed line. Results with moist absorbing aerosol shown as black dashed line.

the absence of the additional moisture (Fig. 9d), leading to little difference in the diurnal average LW forcing (Fig. 9f, Table 9). The net result averaged over the 3-day transition is a modest positive SW forcing that cancels out the negative LW forcing (Table 9).

\section{Impacts on heavily drizzling stratocumulus}

The background aerosol concentrations in our simulations result in negligible drizzle for these conditions. As SCT is often observed in association with precipitation (e.g., Zhou et al., 2015), we next consider the impact of absorbing aerosol on the SCT of heavily drizzling stratocumulus by reducing the $N_{\mathrm{a}}$, sulfate by 6-fold, to $25 \mathrm{mg}^{-1}$. Throughout this section the aerosol layer base is initially at $1.3 \mathrm{~km}$ and the layer does not include additional moisture.

The reduced $N_{\mathrm{a}}$, sulfate is associated with domain-mean drizzle at cloud base reaching $\sim 2 \mathrm{mmd}^{-1}$ each night (Fig. 10f). With drizzle the stratocumulus deck retains the essential features of the PBL growth and of the thinning and dissipation of the stratocumulus layer during the SCT, but exhibits differences associated with a much weaker diurnal cycle (Fig. 10), as also reported by Sandu and Stevens (2011). As discussed in Sandu et al. (2008), a weaker diurnal cycle is attributable to depletion of cloud water and stratification of the PBL via precipitation, which limits the stratocumulus invigoration during the night. A reduced LWP in turn lessens solar heating after sunrise, reducing daytime cloud thinning and breakup.

As seen in Fig. 10f, entrainment of aerosol inhibits drizzle and thereby thickens the stratocumulus layer. This inhibition of drizzle restores more than enough cloud water to overcome PBL drying tendencies from the increased entrainment on day 2. After sunrise, cloud cover falls sharply as the reduced drizzle strengthens the diurnal cycle. Owing to a thicker nocturnal cloud deck and a stronger inversion from aerosol heating aloft, cloud breakup is delayed but amplified on day 2. On day 3 , the aerosol heating in the presence of a stronger diurnal cycle results in a hastened SCT.

The inhibition of drizzle on day 2 allows for greater mixing and entrainment (cf. Stevens et al., 1998) despite the stronger inversion from aerosol heating aloft (Fig. 10d). The deeper PBL is associated with cooler cloud tops that emit less LW radiation, leading to a positive LW forcing during the transition (Table 10). Such positive LW forcing is more than offset by the strong SW forcing attributable to a strong Twomey effect (relative to a cleaner baseline for this heavily drizzling case), and the net impact is therefore an amplified negative forcing (Table 10). 
Table 10. As in Table 9 but for a heavily drizzling baseline $\left(N_{\mathrm{a} \text {, sulfate }}=25 \mathrm{mg}^{-1}\right)$.

\begin{tabular}{|c|c|c|c|c|c|c|c|}
\hline & \multicolumn{3}{|c|}{ Direct forcing } & \multicolumn{3}{|c|}{$\begin{array}{c}\text { Indirect }+ \\
\text { semi-direct forcing }\end{array}$} & \multirow[b]{2}{*}{$\mathrm{SW}+\mathrm{LW}$} \\
\hline & SW & LW & $\mathrm{SW}+\mathrm{LW}$ & SW & LW & $\mathrm{SW}+\mathrm{LW}$ & \\
\hline Day 1 & 0.3 & -0.1 & 0.2 & -0.5 & 0.0 & -0.5 & -0.3 \\
\hline Day 2 & 2.0 & -0.2 & 1.8 & -52.0 & 6.3 & -45.7 & -43.9 \\
\hline Day 3 & -3.4 & -0.0 & -3.4 & -9.4 & 3.4 & -6.0 & -9.4 \\
\hline Mean & -0.4 & -0.1 & -0.5 & -20.6 & 3.2 & -17.4 & -17.9 \\
\hline
\end{tabular}

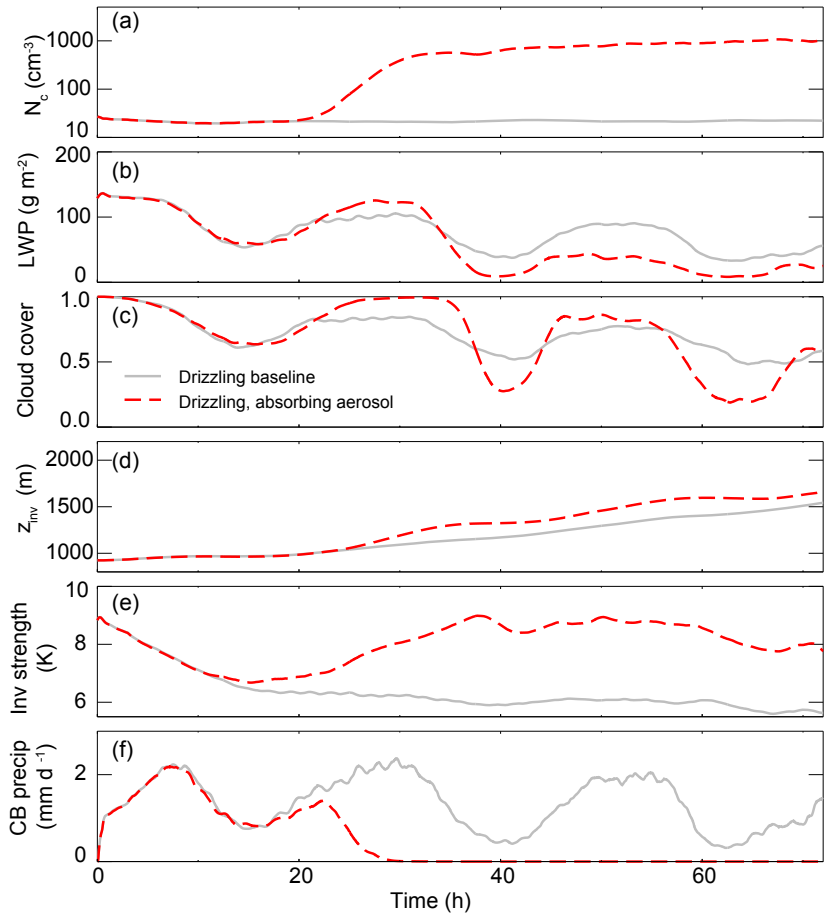

Figure 10. As in Fig. 2 but for a heavily drizzling baseline $\left(N_{\mathrm{a}, \text { sulfate }}=25 \mathrm{mg}^{-1}\right)$.

\section{Discussion and conclusions}

In this study we have examined the impact of an initially overlying layer of absorbing aerosol on the stratocumulusto-cumulus transition (SCT) of lightly and heavily drizzling clouds via large-eddy simulations. Our results indicate that the overlying aerosol can profoundly modify the breakup of stratocumulus as it advects over increasingly warm SSTs. During the transition of lightly drizzling clouds, an overlying absorbing aerosol results in a more broken cloud field, hastening the SCT and strengthening the diurnal cycle. The hastened SCT in our simulations is primarily attributable to an increased number concentration of cloud droplets leading to faster evaporation of more cloud water that enhances entrainment. This result holds in the presence of additional moisture in the aerosol layer and is insensitive to a $400 \mathrm{~m}$ increase in its initial altitude. Drizzle constitutes another degree of complexity. Its inhibition from aerosol entrainment thickens the stratocumulus and leads to a stronger diurnal cloud cycle that ultimately hastens the SCT.

The hastening of the SCT in this study is notable in contrast with Y15, who found the opposite in a similar study. The entrained aerosol in that study leads to increased cloudiness and a delay of the SCT before precipitation develops, suggesting that inhibition of precipitation is not the cause of delayed SCT in Y15. The strength of sedimentation and evaporation effects in the Y15 simulations is not obvious; we do find a delay in the SCT for a lightly drizzling case only when sedimentation and evaporation effects are both omitted (see Appendix B). It is noteworthy that direct numerical simulation (DNS) indicates that the sensitivity of cloud-top entrainment is substantially underpredicted in LES (de Lozar and Mellado, 2017), so in reality the microphysical effects may be considerably stronger than represented here. Another likely source of discrepancy between our studies could be differences in model formulations. Y15 use the System for Atmospheric Modeling (SAM; Khairoutdinov and Randall, 2003), whereas here we use DHARMA (Ackerman et al., 2004). As seen in the intercomparison of de Roode et al. (2016), the evolution of cloudiness in SAM and DHARMA for that study's reference case (following Sandu and Stevens, 2011, from the observational study of Sandu et al., 2010) is notably different in that DHARMA tends to ultimately develop a more broken cloud field than SAM. The cloud cover in DHARMA better resembles the satellite observations of Sandu et al. (2010) than SAM does during the SCT (Fig. 3k in de Roode et al., 2016), but that is not necessarily proof of model skill since case study large-scale forcings tend to be insufficiently constrained by available observations (e.g., Vogelmann et al., 2015), whereas here we neglect consumption of aerosol number (activation into cloud droplets is reversible through evaporation) owing to an absence of constraints on aerosol source terms. In contrast, Y15 include aerosol consumption, and a fixed surface source, which together result in their in-cloud droplet number concentration dropping rapidly to $\mathcal{O}\left(10 \mathrm{~cm}^{-3}\right)$ within the final $12 \mathrm{~h}$ of their control simulation, inducing a dramatic decrease in cloud cover that does not occur when an overlying aerosol 
layer is included. The detailed dynamical and microphysical differences between the studies warrant further investigation, and future observational studies are necessary to provide a firmer foundation for establishing the impact of absorbing aerosol on the timing of SCT.

Our study suggests that even in the case of a hastened transition, an initially overlying absorbing aerosol layer can produce net negative aerosol indirect and semi-direct radiative forcings during SCT. For lightly drizzling stratocumulus, such negative forcing is mainly attributable to greater cloud albedo from a dominant Twomey effect and to negative LW forcing from greater cloud breakup over warmer SSTs and reduced PBL top height from aerosol heating. Diminishing already from the interactions between microphysical and semi-direct processes, when combined with aerosol direct SW forcing, the net SW forcing nearly vanishes, thus becoming even less significant relative to the negative LW forcing during the SCT. We recommend that such sizable LW forcings not be neglected when considering semi-direct aerosol forcings in the context of stratocumulus breakup. Further sensitivity tests (Appendix A) show that when SSA at $0.5 \mu \mathrm{m}$ wavelength decreases further, the negative contributions can be overcome by the large positive SW forcing via direct absorption, leading to net positive aerosol forcings. We find it likely that similar positive forcings occur with an increase in aerosol layer thickness.

When the aerosol layer is initially placed at a higher altitude, the extended duration of aerosol overriding the stratocumulus deck intensifies the positive SW forcing from direct absorption while largely enhancing the negative SW indirect and semi-direct forcings from less LWP reduction owing to less entrained aerosol and a stronger inversion, leading to a more negative net forcing when averaged over the 3-day transition.

A moist layer aloft associated with outflow from a deeper continental PBL tends to intensify the radiative forcings by reducing cloud-top LW cooling and thus convective intensity and increasing the positive SW forcing before contact with the PBL, and by enhancing negative SW forcing after contact via greater LWP resulting from reduced PBL drying. The net effect of the overlying additional moisture is to modestly increase cloud water during the 3-day transition. Absorbing aerosol in the presence of additional moisture tends to break up the cloud more dramatically relative to the effect of absorbing aerosol without additional moisture aloft. The presence of moisture little affects the LW forcing, but leads to substantially more net downward SW flux at TOA. Averaged over the 3-day transition, the positive SW forcing cancels out the negative LW forcing.
We note that the simulations in this study are derived from observations over the northeastern Pacific Ocean (Sandu et al., 2010), whereas the characteristics of the overlying absorbing aerosol layer are based on observations from the southeastern Atlantic (A15). The different large-scale meteorological conditions at these two locations may limit the generality of this study to the SCT over the Atlantic. However, we find it likely that similarly complex interactions (as summarized in Table 4) do occur. Future LES and global modeling studies based on conditions over the southeastern Atlantic should be developed to evaluate the results presented here and in Y15. This study may help inform future analyses primarily by emphasizing the complexity of competing LW and SW effects, and giving some indication of their relative strengths, which lead to a wide range of indirect plus semidirect forcings from slightly positive to $-20 \mathrm{~W} \mathrm{~m}^{-2}$ over our 3-day simulations, depending upon assumptions made (Tables 2, 9, 10, and A1). The duration of time before the absorbing aerosol layer makes contact with the PBL, the strength of drizzle prior to contact, the number concentration of aerosol entrained after contact, and the amount of moisture accompanying the aerosol are all found to be factors of leading potential importance to regional radiative impacts of biomass burning over the southeastern Atlantic and elsewhere.

Data availability. All data of this study are available from the corresponding author (xiaoli.zhou@mail.mcgill.ca). 


\section{Appendix A: Sensitivity to single scattering albedo of absorbing aerosol}

Figure A1 compares the 3-day transition with varying values of single-scattering albedo (SSA, at $0.55 \mathrm{~m}$ wavelength) for the absorbing aerosol. As discussed earlier, the microphysical effect of aerosol acts to greatly reduce cloud water and hasten the SCT by virtue of enhanced entrainment. This effect is also seen in the "SSA $=1$ " case (no absorption) in Fig. A1. The increased entrainment is reflected by the fact that the deepening of the PBL varies little from the baseline simulation, despite substantially reduced cloud cover and LWP. A decrease in SSA from 1 to 0.88 (the value used for the absorbing aerosol throughout the study) serves to strengthen the inversion and enhance the diurnal cycle. These trends are greater when SSA is further reduced to 0.71 , which strengthens the inversion by $\sim 3 \mathrm{~K}$ on day 2 and $\sim 4 \mathrm{~K}$ on day 3 , and deepens the PBL $400 \mathrm{~m}$ less by the end of day 3. The strengthened inversion slightly hinders cloud breakup while still hastening the SCT relative to the baseline (Figs. A1b and c). Although the decrease in SSA amplified the net negative LW forcing via the slower deepening of the $\mathrm{PBL}$, that LW forcing is more than offset by the positive SW forcing attributable to direct absorption by the aerosol, and therefore the 3-day mean radiative forcing increases with the decrease in SSA. Thus, for the strongly absorbing aerosol case $(\mathrm{SSA}=0.71)$ it is seen in Table A1 that the net radiative forcing is positive on average.

\section{Appendix B: Combined effects of overlying absorbing aerosol in the absence of sedimentation and evaporation effects}

As seen in Fig. A2, an overlying absorbing aerosol results in a delayed SCT when sedimentation and evaporation effects are both omitted. The lack of microphysical effects on dynamics isolates the influence of aerosol heating, which increases LWP and especially cloud cover during the night and delays the SCT. We note that Y15 also found a delay in the SCT, but the similarity to this result may be coincidental.
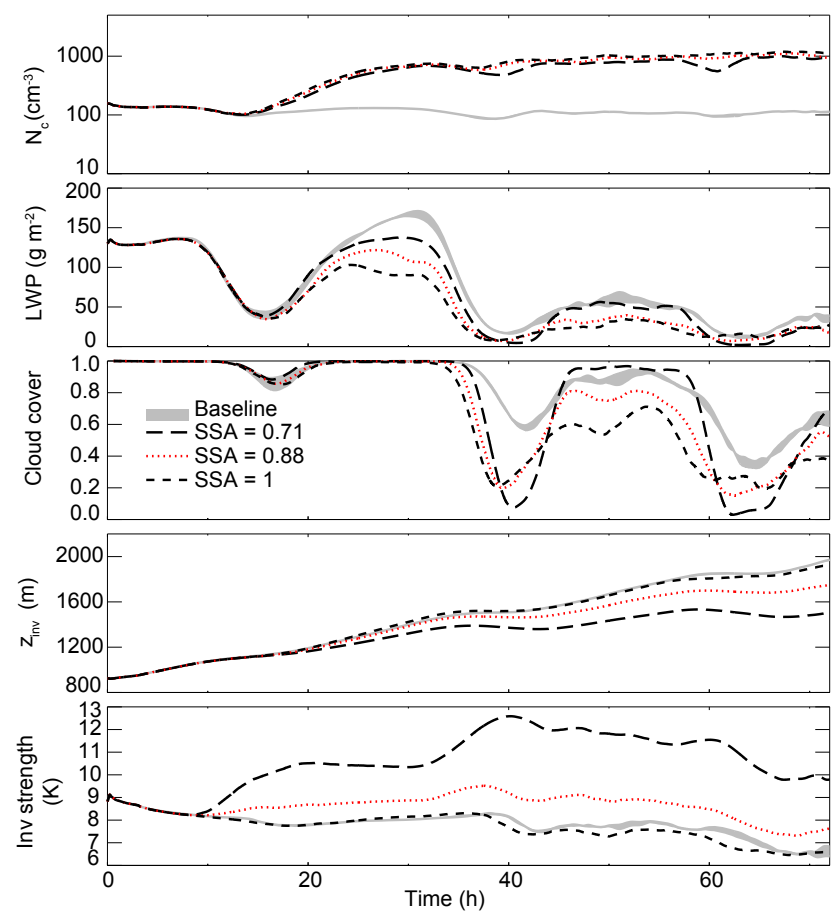

Figure A1. As in Fig. 2. Range of the three-member lightly drizzling baseline ensemble $\left(N_{\mathrm{a}}\right.$, sulfate $\left.=150 \mathrm{mg}^{-1}\right)$ in gray. Varying single scattering albedo (SSA) of absorbing aerosol as given in the legend.

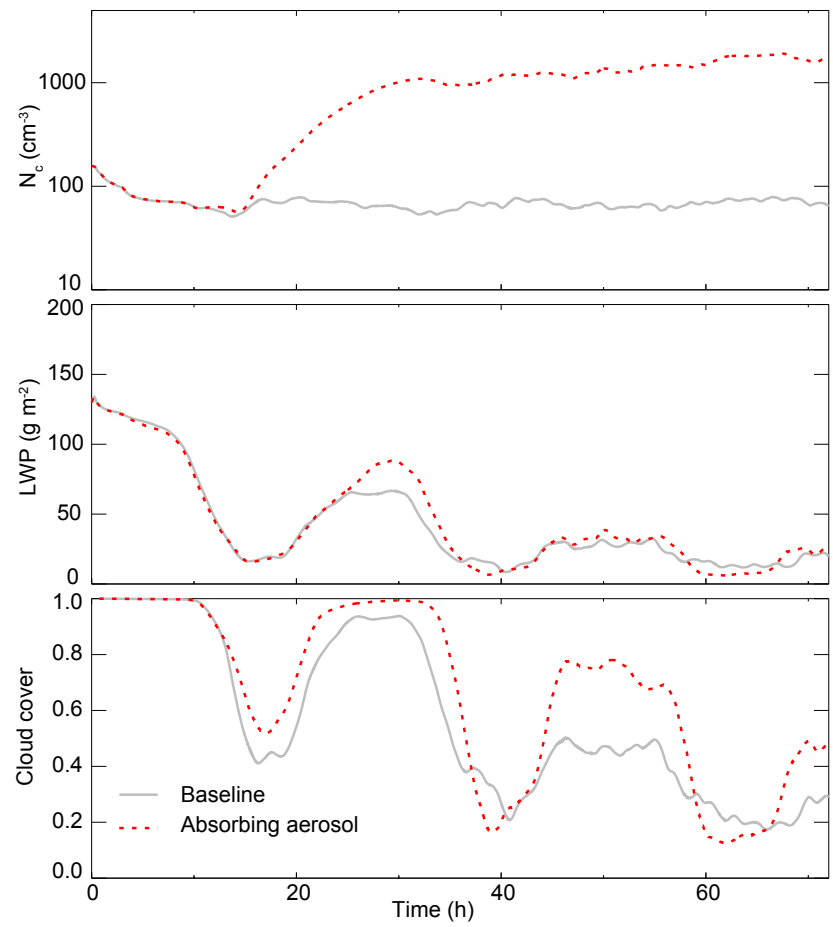

Figure A2. As in Fig. 2 but for a lightly drizzling baseline and with absorbing aerosol in the absence of sedimentation and evaporation effects. 
Table A1. As in Table 2 but for absorbing aerosol with different values of single scattering albedo (SSA), and only showing averages over the 3-day transition. For the last case the aerosol loading is reduced 5-fold.

\begin{tabular}{|c|c|c|c|c|c|c|c|c|}
\hline \multirow[t]{2}{*}{$\begin{array}{l}N_{\mathrm{a}, \text { absorb }} \\
\left(\mathrm{mg}^{-1}\right)\end{array}$} & & \multicolumn{3}{|c|}{ Direct forcing } & \multicolumn{3}{|c|}{$\begin{array}{c}\text { Indirect }+ \\
\text { semi-direct forcing }\end{array}$} & \multirow{2}{*}{$\begin{array}{r}\text { Total } \\
\mathrm{SW}+\mathrm{LW}\end{array}$} \\
\hline & & SW & LW & $\mathrm{SW}+\mathrm{LW}$ & SW & LW & $\mathrm{SW}+\mathrm{LW}$ & \\
\hline \multirow{3}{*}{5000} & $\mathrm{SSA}=0.71$ & 15.9 & -0.2 & 15.7 & -5.1 & -5.2 & -10.3 & 5.4 \\
\hline & $\mathrm{SSA}=0.88$ & 1.5 & -0.2 & 1.3 & -1.1 & -2.9 & -4.0 & -2.7 \\
\hline & $\mathrm{SSA}=1.00$ & -4.9 & -0.1 & -5.0 & 0.8 & -2.5 & -1.7 & -6.7 \\
\hline 1000 & $\mathrm{SSA}=0.88$ & 0.2 & 0.0 & 0.2 & 2.5 & -1.9 & 0.6 & 0.8 \\
\hline
\end{tabular}




\section{The Supplement related to this article is available online at https://doi.org/10.5194/acp-17-12725-2017- supplement.}

Competing interests. The authors declare that they have no conflict of interest.

Acknowledgements. This research was funded by the NASA ORACLES project and the DOE ASR program. Resources supporting this work were provided by the NASA High-End Computing (HEC) Program through the NASA Advanced Supercomputing (NAS) Division at Ames Research Center. We thank Paquita Zuidema and an anonymous reviewer for helpful suggestions.

Edited by: Aijun Ding

Reviewed by: Paquita Zuidema and one anonymous referee

\section{References}

Abdul-Razzak, H. and Ghan, S. J.: A parameterization of aerosol activation 2. Multiple aerosol types, J. Geophys. Res., 105, 68376844, 2000.

Ackerman, A. S., Toon, O. B., and Hobbs, P. V.: Dissipation of marine stratiform clouds and collapse of the marine boundary layer due to the depletion of cloud condensation nuclei by clouds, Science, 262, 226-229, 1993.

Ackerman, A. S., Hobbs, P. V., and Toon, O. B.: A model for particle microphysics, turbulent mixing, and radiative transfer in the stratocumulus-topped marine boundary layer and comparisons with measurements, J. Atmos. Sci., 52, 1204-1236, 1995.

Ackerman, A. S., Toon, O. B., Stevens, D. E., Heymsfield, A. J., Ramanathan, V., and Welton, E. J.: Reduction of tropical cloudiness by soot, Science, 288, 1042-1047, 2000.

Ackerman, A. S., Kirkpatrick, M. P., Stevens, D. E., and Toon, O. B.: The impact of humidity above stratiform clouds on indirect aerosol climate forcing, Nature, 432, 1014-1017, 2004.

Ackerman, A. S., van Zanten, M. C., Stevens, B., Savic-Jovcic, V., Bretherton, C. S., Chlond, A., Golaz, J.-G., Jiang, H., Khairoutdinov, M., Krueger, S. K., Lewellen, D. C., Lock, A., Moeng, C.-H., Nakamura, K. Petters, M. D. Snider, J. R. Weinbrecht, S., and Zulauf, M.: Large-eddy simulations of a drizzling, stratocumulus-topped marine boundary layer, Mon. Weather Rev., 137, 1083-1110, 2009.

Adebiyi, A. A. and Zuidema, P.: The role of the southern African easterly jet in modifying the southeast Atlantic aerosol and cloud environments, Q. J. Roy. Meteor. Soc., 142, 1574-1589, 2016.

Adebiyi, A. A., Zuidema, P., and Abel, S. J.: The convolution of dynamics and moisture with the presence of shortwave absorbing aerosols over the southeast Atlantic, J. Climate, 28, 1997-2024, 2015

Albrecht, B. A.: Aerosols, cloud microphysics, and fractional cloudiness, Science, 245, 1227-1230, 1989.

Bretherton, C. S. and Wyant, M. C.: Moisture transport, lowertropospheric stability, and decoupling of cloud-topped boundary layers, J. Atmos. Sci., 54, 148-167, 1997.
Bretherton, C. S., Blossey, P. N., and Uchida, J.: Cloud droplet sedimentation, entrainment efficiency, and subtropical stratocumulus albedo, Geophys. Res. Lett., 34, L03813, https://doi.org/10.1029/2006GL027648, 2007.

Chand, D., Wood, R., Anderson, T. L., Satheesh, S. K., and Charlson, R. J.: Satellite-derived direct radiative effect of aerosols dependent on cloud cover, Nat. Geosci., 2, 181-184, 2009.

Coakley Jr., J. A. and Walsh, C. D.: Limits to the aerosol indirect radiative effect derived from observations of ship tracks, J. Atmos. Sci., 59, 668-680, 2002.

Cook, J. and Highwood, E. J.: Climate response to tropospheric absorbing aerosols in an intermediate general-circulation model, Q. J. Roy. Meteor. Soc., 130, 175-191, 2004.

de Lozar, A. and Mellado, J. P.: Reduction of the Entrainment Velocity by Cloud Droplet Sedimentation in Stratocumulus, J. Atmos. Sci., 74, 751-765, 2017.

de Roode, S. R., Sandu, I., van der Dussen, J. J., Ackerman, A. S., Blossey, P., Jarecka, D., Lock, A., Siebesma, A. P., and Stevens, B.: Large eddy simulations of EUCLIPSE/GASS Lagrangian stratocumulus to cumulus transitions: Mean state, turbulence, and decoupling, J. Atmos. Sci., 73, 2485-2508, https://doi.org/10.1175/JAS-D-15-0215.1, 2016.

Engelhart, G. J., Hennigan, C. J., Miracolo, M. A., Robinson, A. L., and Pandis, S. N.: Cloud condensation nuclei activity of fresh primary and aged biomass burning aerosol, Atmos. Chem. Phys., 12, 7285-7293, https://doi.org/10.5194/acp12-7285-2012, 2012.

Feingold, G., Jiang, H., and Harrington, J. Y.: On smoke suppression of clouds in Amazonia, Geophys. Res. Lett., 32, L02804, https://doi.org/10.1029/2004GL021369, 2005.

Forster, A., Schouten, S., Baas, M., and Damsté, J. S. S.: MidCretaceous (Albian-Santonian) sea surface temperature record of the tropical Atlantic Ocean, Geology, 35, 919-922, 2007.

Geoffroy, O., Brenguier, J.-L., and Burnet, F.: Parametric representation of the cloud droplet spectra for LES warm bulk microphysical schemes, Atmos. Chem. Phys., 10, 4835-4848, https://doi.org/10.5194/acp-10-4835-2010, 2010.

Ghan, S. J.: Technical Note: Estimating aerosol effects on cloud radiative forcing, Atmos. Chem. Phys., 13, 9971-9974, https://doi.org/10.5194/acp-13-9971-2013, 2013.

Hansen, J., Sato, M., and Ruedy, R.: Radiative forcing and climate response, J. Geophys. Res., 102, 6831-6864, https://doi.org/10.1029/96JD03436, 1997.

Haywood, J., Francis, P., Dubovik, O., Glew, M., and Holben, B.: Comparison of aerosol size distributions, radiative properties, and optical depths determined by aircraft observations and Sun photometers during SAFARI 2000, J. Geophys. Res., 108, 8471, https://doi.org/10.1029/2002JD002250, 2003.

Haywood, J. M., Osborne, S. R., Francis, P. N., Keil, A., Formenti, P., Andrae, M. O., and Kaye, P. H.: The mean physical and optical properties of regional haze dominated by biomass burning aerosol measured from the C-130 aircraft during SAFARI 2000, J. Geophys. Res., 108, 8473 https://doi.org/10.1029/2002JD002226, 2003.

Hindman, E. E., Porch, W. M., Hudson, J. G., and Durkee, P. A.: Ship-produced cloud lines of 13 July 1991, Atmos. Environ., 28 , 3393-3403, 1994.

Jacobson, M. Z.: Control of fossil-fuel particulate black carbon and organic matter, possibly the most effective method 
of slowing global warming, J. Geophys. Res., 107, 4410, https://doi.org/10.1029/2001JD001376, 2002.

Jayaraman, A., Lubin, D., Ramachandran, S., Ramanathan, V., Woodbridge, E., Collins, W. D., and Zalpuri, K. S.: Direct observations of aerosol radiative forcing over the tropical Indian Ocean during the January-February 1996 pre-INDOEX cruise, J. Geophys. Res., 103, 13827-13836, https://doi.org/10.1029/98JD00559, 1998.

Johnson, B. T.: Large-eddy simulations of the semidirect aerosol effect in shallow cumulus regimes, J. Geophys. Res., 110, D14206, https://doi.org/10.1029/2004JD005601, 2005.

Johnson, B. T., Shine, K. P., and Forster, P. M.: The semi-direct aerosol effect: Impact of absorbing aerosols on marine stratocumulus, Q. J. Roy. Meteor. Soc., 130, 1407-1422, 2004.

Keil, A. and Haywood, J. M.: Solar radiative forcing by biomass burning aerosol particles during SAFARI 2000: A case study based on measured aerosol and cloud properties, J. Geophys. Res., 108, 8467, https://doi.org/10.1029/2002JD002315, 2003.

Khairoutdinov, M. F. and Randall, D. A.: Cloud resolving modeling of the ARM summer 1997 IOP: Model formulation, results, uncertainties, and sensitivities, J. Atmos. Sci., 60, 607-625, 2003.

Klein, S. A. and Hartmann, D. L.: The seasonal cycle of low stratiform clouds, J. Climate, 6, 1587-1606, 1993.

Labonne, M., Bréon, F. M., and Chevallier, F.: Injection height of biomass burning aerosols as seen from a spaceborne lidar, Geophys. Res. Lett., 34, L11806, https://doi.org/10.1029/2007GL029311, 2007.

Lindstrot, R., Stengel, M., Schröder, M., Fischer, J., Preusker, R., Schneider, N., Steenbergen, T., and Bojkov, B. R.: A global climatology of total columnar water vapour from SSM/I and MERIS, Earth Syst. Sci. Data, 6, 221-233, https://doi.org/10.5194/essd-6-221-2014, 2014.

Loeb, N. G. and Schuster, G. L.: An observational study of the relationship between cloud, aerosol and meteorology in broken low-level cloud conditions, J. Geophys. Res., 113, D14214, https://doi.org/10.1029/2007JD009763, 2008.

Lohmann, U. and Feichter, J.: Can the direct and semi-direct aerosol effect compete with the indirect effect on a global scale?, Geophys. Res. Lett., 28, 159-161, 2001.

Menon, S., Hansen, J., Nazarenko, L., and Luo, Y.: Climate effects of black carbon aerosols in China and India, Science, 297, 22502253, 2002.

Morrison, H. and Grabowski, W. W.: Modeling supersaturation and subgrid-scale mixing with two-moment bulk warm microphysics, J. Atmos. Sci., 65, 792-812, 2008.

Morrison, H., Curry, J. A., and Khvorostyanov, V. I.: A new doublemoment microphysics parameterization for application in cloud and climate models, Part I: Description, J. Atmos. Sci., 62, 16651677, 2005.

Penner, J. E., Zhang, S. Y., and Chuang, C. C.: Soot and smoke aerosol may not warm climate, J. Geophys. Res., 108, 4657, https://doi.org/10.1029/2003JD003409, 2003.

Petters, M. D. and Kreidenweis, S. M.: A single parameter representation of hygroscopic growth and cloud condensation nucleus activity, Atmos. Chem. Phys., 7, 1961-1971, https://doi.org/10.5194/acp-7-1961-2007, 2007.

Pincus, R. and Baker, M. B.: Effect of precipitation on the albedo susceptibility of clouds in the marine boundary layer, Nature, 372, 250-252, 1994.
Randall, D. A., Coakley Jr., J. A., Lenschow, D. H., Fairall, C. W., and Kropfli, R. A.: Outlook for research on subtropical marine stratification clouds, B. Am. Meteorol. Soc., 65, 1290-1301, 1984.

Sakaeda, N., Wood, R., and Rasch, P. J.: Direct and semidirect aerosol effects of southern African biomass burning aerosol, J. Geophys. Res., 116, D12205, https://doi.org/10.1029/2010JD015540, 2011.

Sandu, I. and Stevens, B.: On the factors modulating the stratocumulus to cumulus transitions, J. Atmos. Sci., 68, 1865-1881, 2011.

Sandu, I., Brenguier, J. L., Geoffroy, O., Thouron, O., and Masson, V.: Aerosol impacts on the diurnal cycle of marine stratocumulus, J. Atmos. Sci., 65, 2705-2718, 2008.

Sandu, I., Stevens, B., and Pincus, R.: On the transitions in marine boundary layer cloudiness, Atmos. Chem. Phys., 10, 2377-2391, https://doi.org/10.5194/acp-10-2377-2010, 2010.

Satheesh, S. K. and Ramanathan, V.: Large differences in tropical aerosol forcing at the top of the atmosphere and Earth's surface, Nature, 405, 60-63, 2000.

Stevens, B., Cotton, W. R., Feingold, G., and Moeng, C.H.: Large eddy simulations of strongly precipitating, shallow, stratocumulus-topped boundary layers, J. Atmos. Sci., 55, 36163638, 1998.

Toon, O. B., McKay, C. P., Ackerman, T. P., and Santhanam, K.: Rapid calculation of radiative heating rates and photodissociation rates in inhomogeneous multiple scattering atmospheres, J. Geophys. Res., 94, 16287-16301, 1989.

Twomey, S.: Pollution and the planetary albedo, Atmos. Environ., 8, 1251-1256, 1974.

Twomey, S.: Aerosols, clouds and radiation, Atmos. Environ. AGen., 25, 2435-2442, 1991.

Vogelmann, A. M., Fridlind, A. M., Toto, T., Endo, S., Lin, W., Wang, J., Feng, S., Zhang, Y., Turner, D. D., Liu, Y., Li, Z., Xie, S., Ackerman, A. S., Zhang, M., and Khairoutdinov, M.: RACORO continental boundary layer cloud investigations. Part I: Case study development and ensemble large-scale forcings, J. Geophys. Res.-Atmos., 120, 5962-5992, https://doi.org/10.1002/2014JD022713, 2015.

Wilcox, E. M.: Stratocumulus cloud thickening beneath layers of absorbing smoke aerosol, Atmos. Chem. Phys., 10, 1176911777, https://doi.org/10.5194/acp-10-11769-2010, 2010.

Wood, R.: Cancellation of aerosol indirect effects in marine stratocumulus through cloud thinning, J. Atmos. Sci., 64, 26572779, 2007.

Wyant, M. C., Bretherton, C. S., Rand, H. A., and Stevens, D. E.: Numerical simulations and a conceptual model of the stratocumulus to trade cumulus transition, J. Atmos. Sci., 54, 168-192, 1997.

Xue, H., Feingold, G., and Stevens, B.: Aerosol effects on clouds, precipitation, and the organization of shallow cumulus convection, J. Atmos. Sci., 65, 392-406, 2008.

Yamaguchi, T., Feingold, G., Kazil, J., and McComiskey, A.: Stratocumulus to cumulus transition in the presence of elevated smoke layers, Geophys. Res. Lett., 42, 10478-10485, 2015.

Zhou, X., Kollias, P., and Lewis, E. R.: Clouds, precipitation, and marine boundary layer structure during the MAGIC field campaign, J. Climate, 28, 2420-2442, 2015. 